\title{
Evaluation of Flexible Strategies to Manage the COVID-19 Pandemic in the Education Sector
}

\author{
Sayem Ahmed ${ }^{1} \cdot$ Hasin Md. Muhtasim Taqi ${ }^{1} \cdot$ Yeasir Iqbal Farabi $^{1} \cdot$ Mohiuddin Sarker $^{1} \cdot$ Syed Mithun Ali $^{2}$ (D) \\ Bathrinath Sankaranarayanan ${ }^{3}$
}

Received: 19 December 2020/Accepted: 12 March 2021/Published online: 9 April 2021

(C) Global Institute of Flexible Systems Management 2021

\begin{abstract}
COVID-19 has had a substantial impact on almost every field including the education sector. Due to the requirements for social distancing, the pandemic has provided an impetus for change in the education sector; technology-based sustainable education platforms not experienced previously have become essential. This research aims to propose flexible strategies to mitigate challenges of COVID-19 pandemic in the education sector of an emerging economy: Bangladesh. A total of 16 challenges and 19 flexible strategies were identified based on stakeholders' inputs and literature review. To evaluate the flexible strategies, a methodology based on Pareto analysis and a revised rough-decision making trial and evaluation
\end{abstract}

Syed Mithun Ali

syed.mithun@gmail.com

Sayem Ahmed

sayem.ipe@aust.edu

Hasin Md. Muhtasim Taqi

muhtasimtaqi.ipe@aust.edu

Yeasir Iqbal Farabi

fyeasiriqbal@gmail.com

Mohiuddin Sarker

mohiuddinsarker01@gmail.com

Bathrinath Sankaranarayanan

bathri@gmail.com

1 Department of Mechanical and Production Engineering, Ahsanullah University of Science and Technology, Dhaka 1208, Bangladesh

2 Department of Industrial and Production Engineering, Bangladesh University of Engineering and Technology, Dhaka, Bangladesh

3 Department of Mechanical Engineering, Kalasalingam Academy of Research and Education, Krishnankoil 626126, Tamil Nadu, India laboratory (rough-DEMATEL) method is proposed. Findings reveal that in the context of the COVID-19 pandemic, 'Maintain social distancing and health protocol,' 'Enhance the communication and collaboration among students and teachers,' 'Financial incentives from government,' 'Utilize modern technologies for digitizing the entire education system,' and 'Know how to engage students in an online environment' are the vital strategies that must be implemented if education continues through E-learning. Because the current pandemic situation is a new experience for many individuals around the world, this study helps to recognize the challenges and to propose effective strategies to solve these challenges so that education does not become stagnant.

Keywords COVID-19 - Education sector · E-learning · Flexible strategies - Revised rough DEMATEL .

Sustainability

\section{Introduction}

Sustainability and flexibility have become growing concerns for educators, students, guardians and policymakers. Institutions can play a vital role in the emergence of sustainable and flexible culture by mitigating the negative consequences of their activities in terms of social, economic, and environmental aspects, and can promote sustainable and flexible initiatives in curricula and research development programs (Fissi et al. 2021). Campus greening can be an important element for institutional sustainability efforts. With effective government policies and funds (Shuqin et al. 2019), and institutionalized approaches (Filho et al. 2015), educational institutions can take initiatives to implement green campus. Safety, security, 
campus culture, organization and management are some indicators of green campus adoption to attain SDGs. A "green institution" implements sustainability into all facets of its operations including institutional structure, curriculum development, campus operations, health and safety initiatives, teaching and learning, research, community involvement, mental and financial support, governance and reporting.

The ability to attain sustainability for health and education by 2030 embraces special challenges in emerging economies. In particular, two goals (Goal 3: maintain good health and well-being and Goal 4: ensure quality education) will require flexible and convenient education strategies (Barteit et al. 2020). The spread of the COVID19 pandemic has created dramatic changes in social engagement and organizations worldwide, and the education field has not been untouched (Blundell et al. 2020). Admittedly, several natural disasters are capable of creating unquantifiable disruption; however, this damage can be controlled by the resilience of systems and infrastructure (D'Adamo and Rosa 2020). Despite the massive global social effect of the COVID-19 pandemic, educational institutions must cope with the transition (Ratten and Jones 2020). The market for goods and manufactured materials has declined, schools have shut down, and some school districts have shifted from direct school control to programs of increased autonomy, transparency, and parental preference (Marsh et al. 2020). Governments across the world have temporarily begun closing down schools and colleges due to COVID-19 outbreaks, and there is significant uncertainty about the reopening of educational institutions (Singh and Singh 2020). According to UNESCO (2020), 59.9\% of overall enrolled learners were impacted by COVID-19 outbreak. Although COVID-19 has touched all tiers of the educational sector from pre-school to tertiary education (Nicola et al. 2020), government policymakers must guarantee the consistency of academic learning for students. Problems have emerged in a lack of technological resources, maintaining students' mental well-being, achieving an appropriate balance between multimedia and screen-free operations, and securing an emphasis on infrastructure and technology (Donitsa-Schmidt and Ramot 2020; Raju 2021).

Consequently, the COVID-19 pandemic is expected to produce the largest disturbance of educational opportunity globally in a generation in the absence of a deliberate and efficient education solution. Thus, the challenges for the education sector that were produced by the COVID-19 outbreak cannot be eliminated until they are recognized, and effective strategies are implemented to overcome them.

The COVID-19 pandemic has had a profoundly negative influence on the global higher education system (Rashid and Yadav 2020), resulting in the complete closure of campuses for some educational institutions, and a serious reduction in the number and form of face-to-face class sessions offered to students for other schools (Izumi et al. 2020). As a result, teachers have quickly changed their teaching methods by transferring as much as possible to digital formats so students can keep learning and interact, despite being taught remotely (Bao 2020; Wilson et al. 2020). Furthermore, Talidong et al. (2020) collected data from the activities of Filipino educators about how they treat anxiety related to the COVID-19 outbreak. Murphy (2020) highlighted post COVID-19 consequences in higher education pedagogy and the necessity of emergency E-learning. Hasan and Bao (2020) analyzed and evaluated the influence of E-learning experiences during the COVID19 pandemic on psychological distress among college students. The aim was to concentrate on urgent safety steps for students. Additionally, Hossain et al. (2020) discussed about the effect of an individual's educational qualifications on their systems thinking skills preferences. So far, since E-learning is assumed to be the preferred form of learning to improve the service quality of education, it may involve both negative and beneficial outcomes (Choudhury and Pattnaik 2020).

There are few studies on the challenges faced by the educational institutions of emerging economies in identifying the performance and functionality of the education sector during COVID-19 outbreak; however, there are numerous studies on the impact of the COVID-19 pandemic in other sectors such as health care (Ju et al. 2020), photovoltaic plants (D'Adamo et al. 2020), and supply chains (Paul and Chowdhury 2020; Karmaker et al. 2021; Polas and Raju 2021). It is obvious that addressing suitable strategies to minimize the impact of the COVID19 pandemic in the education sector remains an issue needing further examination. Multi-criteria decision-making (MCDM) approaches are commonly used by researchers to address multiple problems concerning different criteria in the education sector; for instance, Kahraman et al. (2013) analyzed the investments of government in higher education using fuzzy analytic hierarchy process (AHP) and fuzzy Technique for Order of Preference by Similarity to Ideal Solution (TOPSIS). Ranjan et al. (2015) utilized decision-making trial and evaluation laboratory (DEMATEL) to develop a MCDM framework for educational institutions' performance efficiency to ensure that competent personnel and researchers are reliably produced. Sunder (2016) applied Pareto analysis to demonstrate the Lean Six Sigma (LSS) implementation in higher education institutions. A Pareto analysis was used in deployment of quality instruments in higher education by Milosavljevic et al. (2018). In addition, Sagnak et al. (2017) incorporated fuzzy analytical network procedure 
(ANP) to enhance quality education by implementing the several quality features. Muhammad and Cavus (2017) suggested a fuzzy DEMATEL model for evaluating the interrelationships between assessment parameters for the Learning Management Systems (LMS), their impacts on one another, and the criteria that are most relevant. Song and Cao (2017) combined DEMATEL and rough logic in dealing with uncertain and arbitrary decisions together in product service system development. Khan et al. (2019) developed a new Proximity Indexed Value (PIV) MCDM approach for the rating and assessment of E-learning websites. Song et al. (2020) analyzed the challenges for sustainable online consumption adoption using rough DEMATEL technique. In addition, Chen et al. (2020) developed rough-fuzzy DEMATEL method for smart vehicle service systems to evaluate innovative value propositions.

In order to determine the challenges and strategies of the education sector to fight against pandemics, several types of research have been carried out. See, for example, simulated initiatives for school closures to minimize an influenza epidemic (Lee et al. 2010), shifts in the learning environment during the COVID-19 pandemic (Richmond et al. 2020; Richmond et al. 2020), an analysis of the critical need for pause in the education sector amid COVID-19 crisis (Richmond et al. 2020; Richmond et al. 2020), an intra-period approach of COVID-19 pandemic across 20 countries (Crawford et al. 2020), the impact of COVID-19 on Science, Technology, Engineering, and Mathematics (STEM) education (Sintema 2020), effectiveness of and barriers to online learning (Adarkwah 2020) etc. It should be noted that COVID-19 pandemic challenges vary from previous outbreaks, because it affects a broader, often international geographical region.

To the best of our knowledge, most of the previous studies on flexible strategies to manage the COVID-19 pandemic in the education sector are qualitative in nature. However, this research quantitatively evaluates flexible strategies to manage the COVID-19 pandemic in the education sector using a revised rough DEMATEL method in the context of an emerging economy. The proposed method combines the strength of the DEMATEL in discovering causal relationship and merit of rough sets to deal with the vague environment in manipulating subjective flexible strategies implementation judgments without any priori information. Therefore, this study introduces an integrated approach to concentrate on exploring the interrelations among the flexible strategies and investigating the causeand-effect interactions among the strategies. To the best of our knowledge, no such study has explored the flexible strategies of the education sector with vagueness. In a situation like the COVID-19 pandemic, finding the challenges and strategies in the education sector are complicated. This report aims at supporting education decision making to develop and implement effective education responses to the COVID-19 pandemic and to answer these following questions:

RQ1: What effects may the COVID-19 outbreak have on the education sector?

$R Q 2$ : If this sector considers digital migration, what challenges may come into play?

$R Q 3:$ If educational approaches transition to online assessments, what are the best strategies to mitigate the obstacles that come with this decision, and what is the best way to achieve maximum output by implying new strategies?

$R Q 4$ : Which strategies manage the challenges more favorably?

To address these questions, this research contributes to the literature as follows:

1. To pinpoint the challenges for the education sector before and after the implementation of online learning due to COVID-19.

2. To identify a comprehensive list of flexible strategies to recover from the challenges of COVID-19 outbreak for education sector through extensive literature review.

3. To propose a combination of Pareto analysis and rough DEMATEL methods for efficiently recognizing and prioritizing strategies.

4. To guide the decision-makers through a methodology to make strategic and premeditated decisions to successfully implement strategies of the education sector in emerging economies.

The remaining of this article is ordered as follows: Section 2 comprises the framework to identify the challenges and quantify strategies of educational sector using a combination of Pareto analysis and revised rough DEMATEL method. Data collection, analysis, and implementation of the proposed methodology are also discussed in this section. Section 3 presents the results and discussion of findings and results validation. Section 4 covers the practical and research implications for education leaders and policymakers. Section 5 contains the conclusion and recommendations for future work.

\section{Methodology and Data Collection}

In this section, the education situation in Bangladesh is discussed. Furthermore, the challenges for education sector during and following the COVID-19 pandemic and flexible strategies to overcome those challenges are identified. Then the strategies proposed in defense of these challenges are analyzed to develop an effective education system. The 
framework for identifying flexible strategies to overcome the challenges is shown in Fig. 1.

\section{Study Background}

COVID-19 has impacted global education sectors by closing several institutions to lessen the current outbreak and potentially by forcing a majority of students out of educational institutions entirely. The effect of COVID-19 on low-income countries such as Bangladesh has been disastrous. Bangladesh is not a coronavirus free country, and almost 40 million students remain out of school until the outbreak returns to a more manageable level of infection (Emon et al. 2020). Currently, Bangladesh has prolonged the closure of all educational institutions several times; however, COVID-19 severely affects Bangladeshi students for several critical reasons. In Bangladesh, students are anxious about being admitted to higher secondary colleges, and to both national and foreign universities. Several institutions offer virtual classes, although many access challenges exist, including low internet connectivity and speed, high prices for internet data and smart gadgets, and students not being able to participate in online education due to a family crisis. If the scenario persists for the long term, many students in Bangladesh will suffer substantially. The aim of this research is to concentrate on emerging problems of the COVID-19 pandemic and its potential responses through utilizing advanced technologies while maintaining mandated social distancing and health protocols.

Investigate the challenges of education sector amid COVID-19 from extant literature

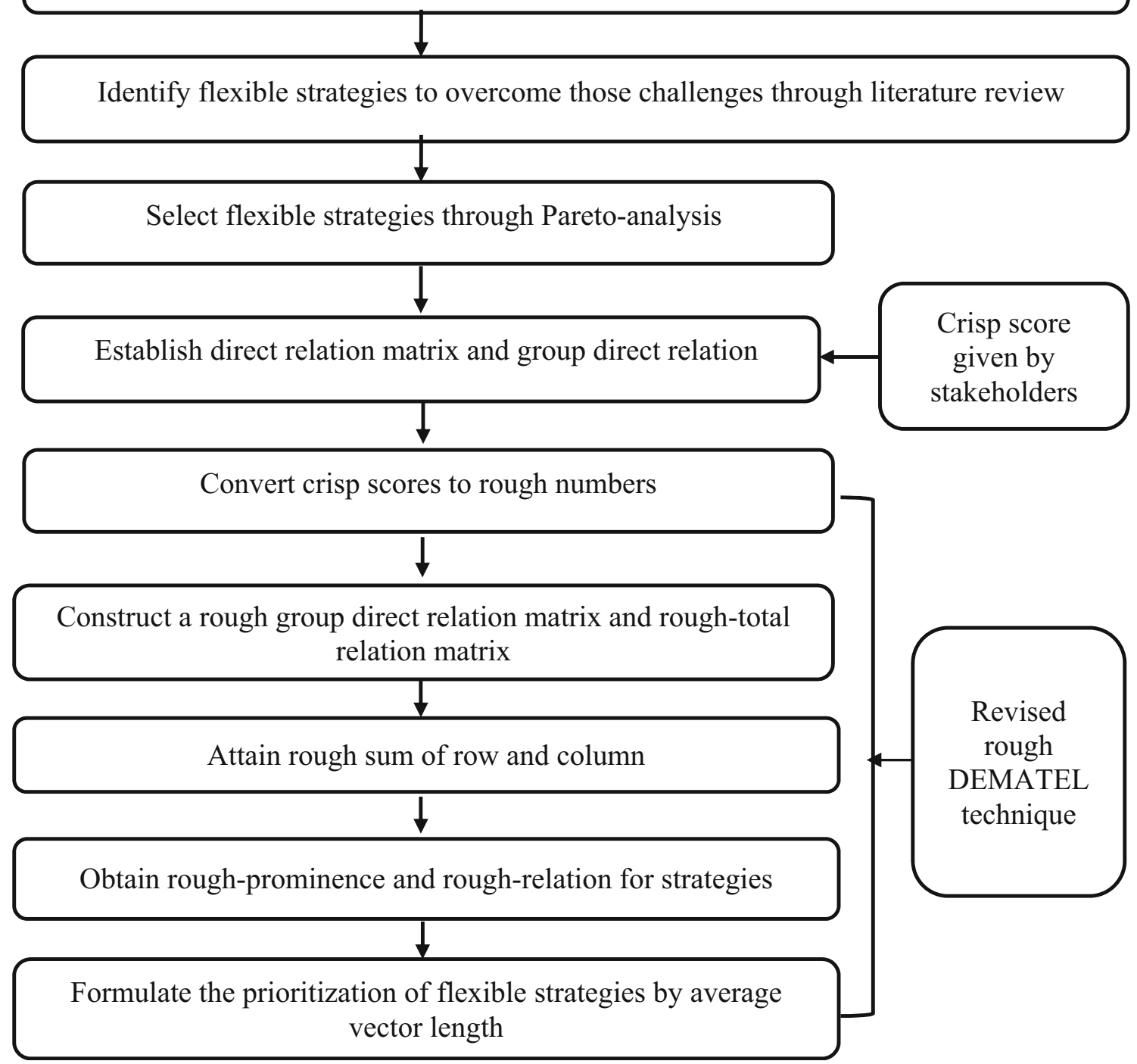

Fig. 1 The framework for identifying flexible strategies to manage COVID-19 pandemic 


\section{Identification of the Challenges on the Education Sector}

The initiation of investigating challenges has been established through an extensive literature review on education, distance learning, and risks focused on this field. These challenges are divided into before and after implementation of online learning. In this research, sixteen critical challenges are identified for the education sector. Challenges for education sector during COVID-19 before and after implementation of E-learning are presented in Tables 1 and 2 , respectively.

\section{Flexible Strategies to Overcome the Challenges Caused by COVID-19 Pandemic}

The COVID-19 pandemic is expected to produce the largest disturbance in education opportunities globally in a decade in the absence of a deliberate and successful education solution (Reimers and Andreas 2020). Appropriate flexible strategies must be considered in order to alleviate the challenges and threats that the pandemic situation has generated. Flexible strategies can be described as a competence to continuously improve institutional efficiency and productivity by introducing and implementing certain initiatives (Shukla et al. 2019; Evans and Bahrami 2020). In this study the flexible strategies are chosen through a combination of results based on literature, stakeholders'

Table 1 Challenges for education sector amid COVID-19 before implementation of E-learning

\begin{tabular}{|c|c|c|c|}
\hline Code & Challenges & Description & References \\
\hline $\mathrm{C} 1$ & Lack of instructional design & $\begin{array}{l}\text { To fulfill the goals of the institution in teaching online, it requires } \\
\text { consistency of content, objective clarification, learning methods, and } \\
\text { learning psychology. Inappropriate vision, guidelines and plans for } \\
\text { E-learning can be detrimental for the development of education }\end{array}$ & $\begin{array}{l}\text { (Alqahtani and Rajkhan } \\
\text { 2020) }\end{array}$ \\
\hline $\mathrm{C} 2$ & $\begin{array}{l}\text { Absence of online learning } \\
\text { facilities }\end{array}$ & $\begin{array}{l}\text { Institutions face obstacles to ensure stable network along with quality of } \\
\text { E-learning products and services. Lack of E-learning facilities that } \\
\text { students could use to connect with their instructors and peers hinder the } \\
\text { progress of online education }\end{array}$ & $\begin{array}{l}\text { (Martin et al. 2020; } \\
\text { Sintema 2020) }\end{array}$ \\
\hline $\mathrm{C} 3$ & $\begin{array}{l}\text { Chaotic learning environment at } \\
\text { home }\end{array}$ & $\begin{array}{l}\text { In most of low and medium-income families, students don't have a quiet } \\
\text { place to read in their houses, especially if it is a joint family. Difficulties } \\
\text { may arise from the students' home environment, such as interference } \\
\text { from family members (younger and older siblings) which affect students' } \\
\text { concentration on learning. Activities of family members can cause } \\
\text { distractions that reduce the concentration necessary to understand the } \\
\text { subject matter }\end{array}$ & (Zar et al. 2020) \\
\hline $\mathrm{C} 4$ & $\begin{array}{l}\text { Inadequate preparedness of } \\
\text { institutions and teachers }\end{array}$ & $\begin{array}{l}\text { When it comes to offer online teaching and distance learning, there is not } \\
\text { much systematic framework and preparedness. Lack of provision of } \\
\text { training courses to learners and instructors about the online learning } \\
\text { platform }\end{array}$ & $\begin{array}{l}\text { (Richmond, et al. 2020; } \\
\text { Richmond et al. 2020) }\end{array}$ \\
\hline $\mathrm{C} 5$ & $\begin{array}{l}\text { Institutional practices for using } \\
\text { digital technologies effectively }\end{array}$ & $\begin{array}{l}\text { Inadequate use of digital and communications technologies such as learning } \\
\text { management system (LMS), video collaboration applications, etc., can } \\
\text { affect the consistency of learning }\end{array}$ & $\begin{array}{l}\text { (König et al. 2020; } \\
\text { Sushil 2015) }\end{array}$ \\
\hline C6 & $\begin{array}{l}\text { Professional and digital } \\
\text { collaboration among teachers }\end{array}$ & $\begin{array}{l}\text { Not having provision of interaction among the instructors induces } \\
\text { insufficient professional collaboration and learning for educators to } \\
\text { successfully run the digital platform }\end{array}$ & $\begin{array}{l}\text { (Alqahtani and Rajkhan } \\
\text { 2020) }\end{array}$ \\
\hline $\mathrm{C} 7$ & $\begin{array}{l}\text { Lack of development budget and } \\
\text { investments from institutions }\end{array}$ & $\begin{array}{l}\text { Modern instruments and strategies such as E-learning, online instructional } \\
\text { tools, home teaching, interactive classroom strategies may not be feasible } \\
\text { due to weak economic condition of the institutions }\end{array}$ & $\begin{array}{l}\text { (Acharya 2019; Lewin } \\
\text { 2020) }\end{array}$ \\
\hline $\mathrm{C} 8$ & $\begin{array}{l}\text { Poor socio-economic conditions } \\
\text { of the citizens }\end{array}$ & $\begin{array}{l}\text { Weak socio-economic conditions could not enable citizens in remote } \\
\text { regions to implement and use digital channels. Moreover, due to the } \\
\text { COVID-19, impoverished students need to contribute to family income as } \\
\text { main earning members of family may not have their jobs or earnings }\end{array}$ & (Kharbikar et al. 2020) \\
\hline C9 & $\begin{array}{l}\text { Lack of government and } \\
\text { international support }\end{array}$ & $\begin{array}{l}\text { The state of the national economy will not have the strength after COVID- } \\
19 \text { to completely cover school curriculum costs. Donor investment to } \\
\text { finance the education system in low and middle-income countries is also } \\
\text { projected to decline since the donor countries have also not been spared } \\
\text { by the COVID-19 pandemic }\end{array}$ & (Sintema 2020) \\
\hline
\end{tabular}


Table 2 Challenges for education sector amid COVID-19 after implementation of E-learning

\begin{tabular}{|c|c|c|c|}
\hline Code & Challenges & Description & References \\
\hline $\mathrm{C} 10$ & Lack in practical teaching & $\begin{array}{l}\text { Students may be deprived of hands-on knowledge and understanding of the } \\
\text { essence of education due to the present lack of practical instruction in } \\
\text { distance learning }\end{array}$ & (Franchi 2020) \\
\hline $\mathrm{C} 11$ & $\begin{array}{l}\text { Fear of knowledge gap among } \\
\text { future instructors }\end{array}$ & $\begin{array}{l}\text { The absence of absolute and sustained exposure to a variety of teaching and } \\
\text { learning approaches will have a profound effect on the strategies and } \\
\text { techniques of future instructors }\end{array}$ & (Franchi 2020) \\
\hline $\mathrm{C} 12$ & Ensuring quality assessments & $\begin{array}{l}\text { Ensuring proper assessment policies to evaluate the students along with the } \\
\text { ability to plan for learning progress during E-learning are critical challenges } \\
\text { for institutions }\end{array}$ & (Evans et al. 2020) \\
\hline $\mathrm{C} 13$ & Turning away from learning & $\begin{array}{l}\text { Students from low-income families cannot afford to buy electronics gadgets, } \\
\text { smart devices, internet, bandwidth, etc., and fail to continue their education } \\
\text { online }\end{array}$ & (Drane et al. 2020) \\
\hline $\mathrm{C} 14$ & Emotional discomfort and anxiety & $\begin{array}{l}\text { As students begin to lose institutional involvement, psychological disorder } \\
\text { such as depression and anxiety among learners can increase }\end{array}$ & $\begin{array}{l}\text { (Drane et al. 2020; } \\
\text { Pikulski et al. } \\
\text { 2020) }\end{array}$ \\
\hline $\mathrm{C} 15$ & $\begin{array}{l}\text { Increasing physiological stress } \\
\text { among students and instructors }\end{array}$ & $\begin{array}{l}\text { Excess use of electronics devices and gadgets to attend the classes and exams } \\
\text { may create severe physiological stress such as eye irritation, headache, etc. }\end{array}$ & (Araújo el al. 2020) \\
\hline $\mathrm{C} 16$ & $\begin{array}{l}\text { Loss of direct interactions with } \\
\text { peers }\end{array}$ & $\begin{array}{l}\text { The absence of face-to-face interaction with learners and educators may } \\
\text { possibly stunt the growth of students. The simplicity of communication and } \\
\text { the exchange of learning experiences with other learners has become a } \\
\text { challenge for online learning }\end{array}$ & (Evans et al. 2020) \\
\hline
\end{tabular}

inputs, Pareto analysis, and rough-DEMATEL method. The rough-DEMATEL method further helped to rank the strategies according to their impact. To identify the possible strategies to overcome the challenges, an extant literature review has been performed to identify most appropriate strategies to tackle the challenges of education and distance learning during COVID-19 outbreak for emerging economies. Flexible strategies for the education sector amid COVID-19 pandemic are presented in Table 3.

After identifying the strategies to tackle the COVID-19 pandemic in the education sector, a Pareto analysis (Kaur et al. 2019) was used to filter the most effective strategies. The Pareto analysis is a statistical tool to differentiate between vital elements and nonessential ones based on experts feedback (Kumar et al. 2019). Kaur et al. (2019) implemented the Pareto analysis to identify critical barriers to green supply chain practices, whereas Tembo Silungwe and Khatleli (2020) implemented the Pareto principle to analyze risks in building sectors. The Pareto analysis has been used in this study to figure out the most appropriate strategies to be applied in response to the challenges encountered. The obtained strategies have been divided into four different categories based on stakeholders' opinions. Then, primary research is conducted by performing an online survey on 200 individuals of several public and private educational institution composed of secondary, higher secondary and tertiary level to obtain the data for the research. In this study, respondents who have adequate knowledge of online education along with educational policy are chosen. Moreover, it is ensured that the participants have a proper understanding of the education sector in emerging economies, play an active role in policymaking in their respective institutions. This research involves stakeholders from all the levels of the education sector to ensure that the findings reflect the overall scenario of the education sector during this pandemic. A questionnaire was designed to gather information from the respondents to conduct the survey (see Appendix 2). The questionnaire is circulated via email and through social media to individuals as they are the most effective and popular survey choice right now. Follow-up calls are made to the respondents after e-mailing and distributing the questionnaires to check whether they had received the message. The follow-up calls have improved and accelerated the number of responses. A total of 550 e-mail invites were sent and 284 survey replies were received, 200 of which were kept for the initial analysis. A total of 84 incomplete surveys were refused, resulting in a total response rate of $51.63 \%$. The profile of the respondents is presented in Table 4.

The information obtained from the questionnaire is further used for Pareto analysis. To find out the best strategies among the categories, Pareto analysis is performed on four distinct categories and twelve strategies have been selected from nineteen strategies through the Pareto analysis. The results are represented graphically for 
Table 3 Flexible strategies for the education sector to manage COVID-19 pandemic

\begin{tabular}{llc}
\hline No Flexible strategies & Description & References \\
\hline
\end{tabular}

1 Enabling social learning connections with educators and their peers

2 Curriculum design framework for online learning

3 Utilize modern technologies for digitizing the entire education system

4 Promote active facilitation and learning support (including feedback)

5 Know how to engage students in an online environment

6 Develop alternative means of delivery

7 Ensure financial support for the most vulnerable students and families

8 Appropriate mechanisms of student assessment

9 Maintain social distancing and health protocol

10 Financial incentives from government

11 Develop a communications plan between the faculties and administration

12 Expansion of welfare programs to provide mental support

13 Public-private partnership for education system development

14 Enhance the communication and collaboration among students and teachers

15 Just-in-time professional development for teachers and parents

16 Develop a plan for continuity of operations amid COVID-19

17 Guidance about the safe use of screen time and online tools

18 Enhancing teacher intrinsic motivation
Online learners may become focused and more involved in their courses through effective interactions with peers, teachers, and content

Curriculum needs to be restructured for successful online education and prevention of poor-quality educational experience in distance learning

Digitalizing the whole education sector by adopting advanced modern technologies and using online learning tools to provide training and capacity building programs for teachers and students

Utilizing video conferencing and other interactive methods to allow educators and students to associate with one another simultaneously regardless of whether they are not at a similar spot

Apply different interactive techniques and opportunities to encourage students' involvement in online environment

If an internet based educational approach is not feasible, create substitute methods for delivering such as TV shows, broadcasts, radio programs and learning packages in digital structure

Ensure sufficient financial assistance for needy students during the introduction of the digitalized educational program

Unlike traditional assessment, offer alternate provisions of online assessment based on assignments, brainstorming ideas, critical thinking, projects, and other features that may help restrict any potential possibilities for cheating

Health protection measures for students and staff in case of physical presences due to administrative works and practical classes

Government should make sure that school officials get the financial, (Maher et al. 2020) operational, and emotional assistance as well as increase the allocated budget for educational institutions to allow them to handle all the losses incurred

Proper communication between faculties and administration is a must to promote the adoption of the education policies across different channels

In order to enrich young minds during this vulnerable situation, students' welfare programs and other social programs are necessary to give them mental strength

Public-private collaboration in the educational system is needed to strengthen the education infrastructure in terms of efficiency and consistency

Improve interaction and coordination with students and teachers so that teachers can handle and facilitate the learning of students successfully in the new environment, through direct supervision or advice

Build a just-in-time professional development mechanism for teachers and parents to be able to assist students with the modern teaching method

A recovery plan for continuation of operations should be established by each educational institution. Education authorities should provide samples of effective plans of different institutions to learn from those plans

Schools can provide learners and families with information on the healthy use of screen time and educational resources to maintain the well-being and emotional health of students

Support teachers technologically, instructionally, and financially to (Beteille et al. 2020) ensure teacher effectiveness
(Gayithri et al. 2020)

(Richmond et al. 2020;

Richmond et al. 2020)

(Evans et al. 2020)

(Richmond et al. 2020;

Richmond et al. 2020)

(Martin and Bolliger 2018)

(Reimers and Andreas 2020)

(Drane et al. 2020; Richmond et al. 2020; Richmond et al. 2020)

(Evans et al. 2020)

(Alqahtani and Rajkhan 2020)

(Bokde et al. 2020)

Bokde et al. 2020)

(Sebastian and Nikol 2020)

(Bokde et al. 2020)

(Reimers and Andreas 2020)

(Medrano et al. 2020; Qin et al. 2020) 
Table 3 continued

\begin{tabular}{llll}
\hline No & Flexible strategies & Description & References \\
\hline $\begin{array}{l}\text { Restructuring through resilience and } \\
\text { flexibility }\end{array}$ & $\begin{array}{r}\text { The restructuring of the educational sector is vital to strengthen } \\
\text { teaching and learning and to recover from the challenges faced } \\
\text { during COVID-19 pandemic }\end{array}$ & (Van den Beemt et al. 2020) \\
\hline
\end{tabular}

Table 4 Profile of the respondents $(n=200)$

\begin{tabular}{lll}
\hline Variable & $\begin{array}{l}\text { Number of } \\
\text { respondents }\end{array}$ & $\begin{array}{l}\text { Percentage of } \\
\text { respondents }\end{array}$ \\
\hline Gender & & \\
Male & 137 & $68.5 \%$ \\
Female & 63 & $31.5 \%$ \\
Institution & & \\
Public & 81 & $40.5 \%$ \\
Private & 119 & $59.5 \%$ \\
Occupation/position & \\
Students & 104 & $52 \%$ \\
Guardian & 26 & $13 \%$ \\
Lecturer & 20 & $10 \%$ \\
Assistant & 16 & $8 \%$ \\
$\quad$ professor & & $6 \%$ \\
Associate & 12 & $5 \%$ \\
$\quad$ professor & & $6 \%$ \\
Professor & 10 & $46 \%$ \\
Policymakers & 12 & $27 \%$ \\
Age & & $18 \%$ \\
$16-25$ & 92 & \\
$26-35$ & 54 &
\end{tabular}

four different categories to provide a simple visualization of the strategies and their impact.

Table 13 represents 'Category A: Initial framework building' with six strategies defined from literature work. Figure 2 displays the findings obtained in Table 13, which displays the category's most effective strategies. Relative to other methods in the category, the curriculum design framework for online learning has the highest frequency. The ability to engage students in online teaching and to use modern technology for digitizing the education system have also earned substantial ratings because they are far more influential than other strategies.

Table 14 represents 'Category B: Planning and preparation,' with six strategies defined from literature work. Figure 3 reflects the planning and preparation strategies. The student assessment mechanism obtained the most frequency from the data collected through the survey. If the assessment processes are not appropriate, it may challenge the entire student evaluation processes. That is why, as the pandemic situation goes on, the whole planning and preparation process needs to be carried out with resilience and flexibility, preserving social distance.

Table 15 presents 'Category C: Collaborative communication.' Resilient contact between students and teachers is of enormous importance in order to establish a proper education system in the midst of a pandemic. In addition, collaboration between faculty and administration also plays a key role in online teaching, monitoring, and evaluation. Figure 4 helps to visualize which strategy must be emphasized in the category, among other strategies.

Table 16 presents the effective strategies obtained on the basis of 'Category D: Financial assistance, support and guidance.' The strategies are depicted in graphical form as shown in Fig. 5 which represents the most important strategies to be considered.

\section{Evaluation of Causal Relationships Among Strategies}

A revised rough DEMATEL method was used to rank the strategies and effectively model the causal relationships among the twelve significant strategies found through the Pareto analysis. This study integrates merit of DEMATEL in revealing causal interactions and capacity (Chirra and Kumar 2018) of rough set approach in controlling vagueness and subjectivity judgments with little priori information. The DEMATEL is an effective approach to investigating the interactions among flexible strategies and graphically portraying the complex causal relations among the strategies through cause and effect diagram (Banik et al. 2020). Although the traditional DEMATEL is successful in exploring the cause and effect interactions among strategies, it lacks a flexible manipulation mechanism to exploit contextual and ambiguous decisions (Song and Cao 2017). Therefore, establishment of a systematic framework for assessing and evaluating interrelationships among flexible strategies for the education sector under vague environment is crucial. Some researchers implement fuzzy logic to deal with vagueness and subjectivity, but fuzzy approaches need more prior information (e.g., fuzzy 
Fig. 2 Pareto chart of strategies of Category A: Initial framework building

Fig. 3 Pareto chart of strategies of Category B: Planning and preparation
Fig. 4 Pareto chart of strategies of Category C: Collaborative communication
Category A: Initial framework building

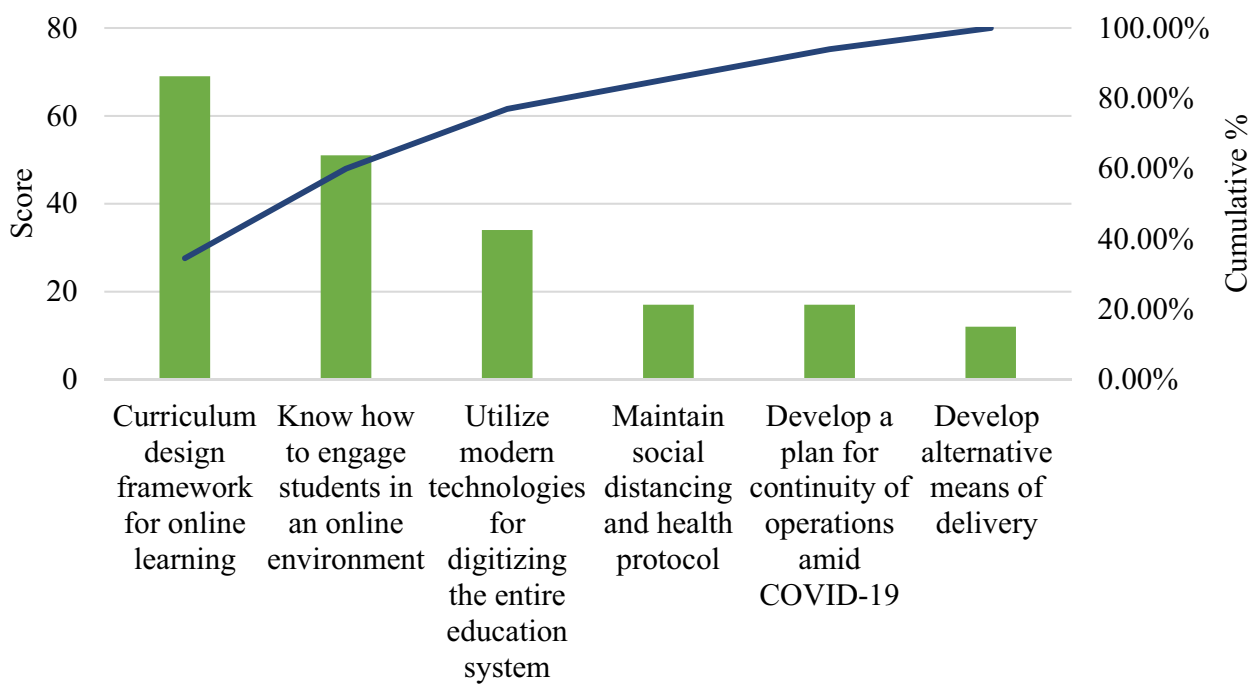

Category B: Planning and preparation
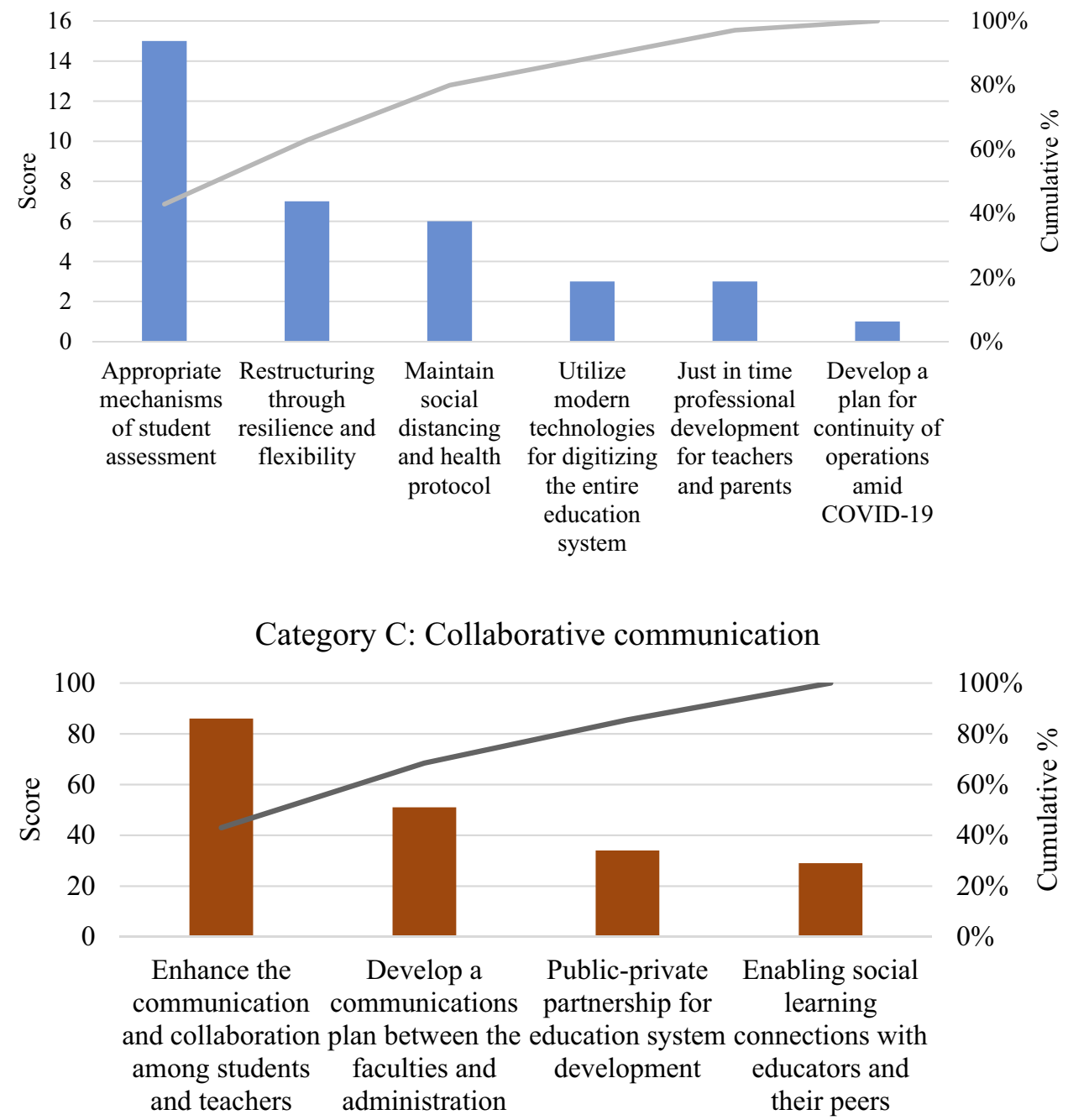
Fig. 5 Pareto chart of strategies of Category D: Financial assistance, support and guidance

\section{Category D: Financial assistance, support and guidance}

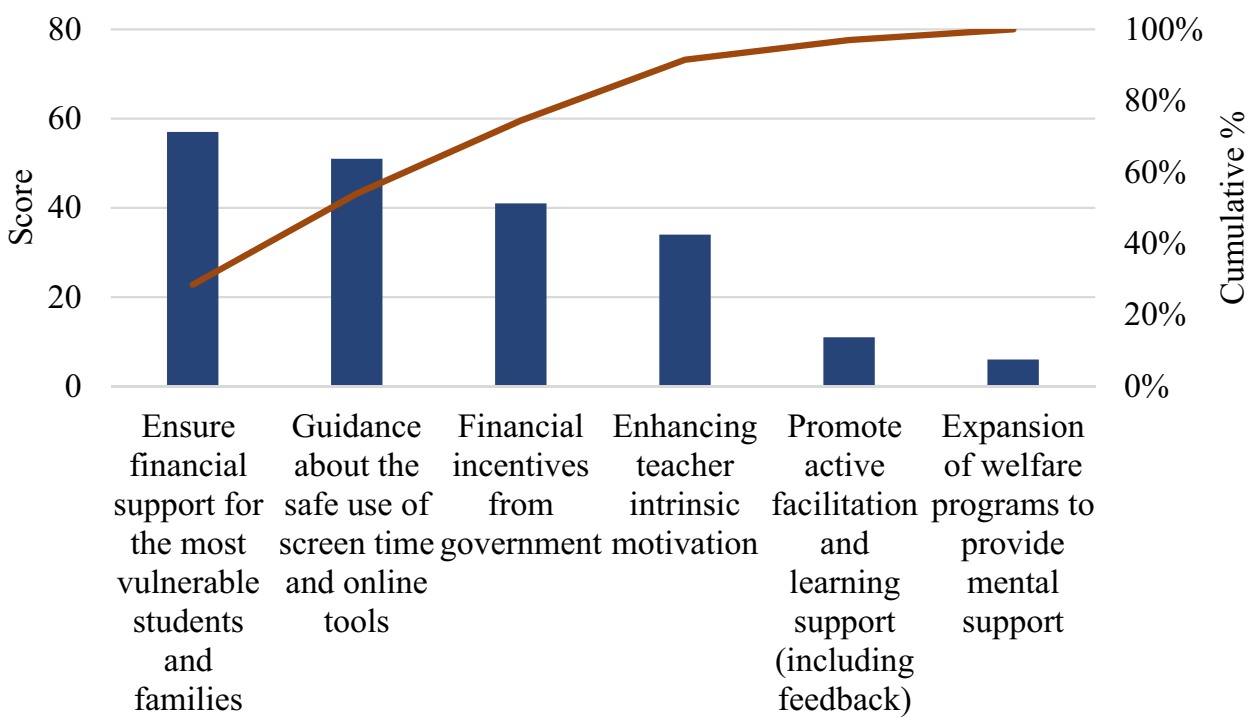

membership and non-membership function, distribution of data) (Song and Cao 2017). However, compared to the traditional DEMATEL method and fuzzy approaches, the revised rough-DEMATEL has high judgment flexibility for flexible strategies adoption without any prior information. To eliminate vagueness and remove uncertainties, rough set theory plays a crucial role (Sambasivam et al. 2020). Hence, in this study, the revised rough DEMATEL framework is used to obtain more precise analysis.

Furthermore, rough-prominence as well as rough-relation are formulated to obtain average vector length (AVL), which is used to achieve weight and rank of the most predominant strategies. In addition, the implication of AVL in the current rough-DEMATEL removes the additional de-roughness calculation. According to the work of Liu and Ming (2019), the revised rough-DEMATEL not only accommodates roughness of non-prior expert decisions but also eradicates numerous de-roughness operators on roughprominence and rough-relation through revised AVL operator.

\section{Establish Initial Direct-relation and Group Initial Direct- relation Matrix for Flexible Strategies}

The initial direct-relation matrix $\left[r_{i j}^{k}\right]_{n \times n}, \mathrm{k}=1,2, \ldots, \mathrm{m}$ is given by $k^{\text {th }}$ expert, $r_{i j}^{k}$ denotes influence degree of $i^{\text {th }}$ strategy with respect to $j^{\text {th }}$ strategy provided by $k^{\text {th }}$ expert. The direct relation matrix among strategies is as follows:

$D_{k}=\left[\begin{array}{cccc}1 & r_{12}^{k} & \cdots & r_{1 n}^{k} \\ r_{21}^{k} & 1 & \cdots & r_{2 n}^{k} \\ \vdots & \vdots & \ddots & \vdots \\ r_{n 1}^{k} & r_{n 2}^{k} & \cdots & 1\end{array}\right] ; i, j=1,2, \ldots \ldots, n$
Here $\mathrm{m}$ is the number of experts and $\mathrm{n}$ is the number of strategies.

Then to initiate group initial direct-relation matrix, $\mathrm{m}$ experts are invited to make pair-wise comparisons in terms of crisp scores for the strategies. The ratings are set following this order (Very high influence $=4$, high influence $=3$, medium influence $=2$, low influence $=1$ ).

The group initial direct relation matrix is formulated by following Eq. (2).

$\tilde{G}=\left[\tilde{r}_{i j}\right]_{n \times n}=\left[\begin{array}{cccc}1 & \tilde{r}_{12} & \cdots & \tilde{r}_{1 n} \\ \tilde{r}_{21} & 1 & \cdots & \tilde{r}_{2 n} \\ \vdots & \vdots & \ddots & \vdots \\ \tilde{r}_{n 1} & \tilde{r}_{n 2} & \cdots & 1\end{array}\right]$

Here $\tilde{\mathrm{r}}_{i j}=\left\{r_{i j}^{1}, r_{i j}^{2}, \ldots, r_{i j}^{k}, \ldots, r_{i j}^{m}\right\}$

\section{Construct Group Rough Direct-relation Matrix for Flexible Strategies}

Consider that there is a set of $\mathrm{m}$ classes of expert opinion, $\mathrm{F}=\left\{r_{i j}^{1}, r_{i j}^{2}, \ldots ., r_{i j}^{k}, \ldots, r_{i j}^{m}\right\}$, which are in the order of $r_{i j}^{1}<r_{i j}^{2}<\ldots .<r_{i j}^{k}<\ldots .<r_{i j}^{m}$. $\mathrm{U}$ is the universe including all the objects and $\mathrm{W}$ is an arbitrary object of $\mathrm{U}$, and then the lower estimation of $r_{i j}^{k}$ and the upper estimation of $r_{i j}^{k}$ can be defined as:

Lower estimation:

$\underline{\operatorname{Est}}\left(r_{\mathrm{ij}}^{k}\right)=\cup\left\{W \in U / F(W) \leq r_{i j}^{k}\right\}$

Upper estimation:

$\overline{\operatorname{Est}}\left(r_{\mathrm{ij}}^{k}\right)=\cup\{W \in U / F(W) \geq\} r_{i j}^{k}$

Here $r_{i j}^{k}$ can be represented as rough number, which can be 
defined by lower limit $\underline{\lim }\left(r_{i j}^{k}\right)$ and upper limit $\overline{\lim }\left(r_{i j}^{k}\right)$ as follows:

$\underline{\lim }\left(r_{\mathrm{ij}}^{k}\right)=\frac{\sum_{m=1}^{O_{\mathrm{ij}}} P_{\mathrm{ij}}}{O_{\mathrm{ijL}}}$

$\varlimsup\left(r_{\mathrm{ij}}^{k}\right)=\frac{\sum_{m=1}^{O_{\mathrm{ij \textrm {U }}}} Q_{\mathrm{ij}}}{O_{\mathrm{ij \textrm {U }}}}$

$P_{i j}$ and $Q_{i j}$ are the elements of lower and upper approximation for $r_{i j}^{k}$, whereas $O_{i j L}$ and $O_{i j U}$ are the number of objects included in the lower approximation and upper approximation of $r_{i j}^{k}$, respectively.

Following Eqs. 3-6, all the crisp judgments on flexible strategies, element $r_{i j}^{k}$ in group direct-relation matrix $\tilde{\mathrm{G}}$ can be converted into rough number $\mathrm{RN}\left(\tilde{\mathrm{r}}_{i j}\right)$.

$$
\begin{aligned}
\mathrm{RN}\left(\tilde{r}_{\mathrm{ij}}\right) & =\left[\tilde{r}_{\mathrm{ij}}^{\mathrm{kL}}, r_{\mathrm{ij}}^{\mathrm{kU}}\right] \\
& =\left\{\tilde{r}_{\mathrm{ij}}^{1 L}, \tilde{r}_{\mathrm{ij}}^{1 U}\left[\tilde{r}_{\mathrm{ij}}^{2 L}, \tilde{r}_{\mathrm{ij}}^{2 U}\right], \ldots\left[r_{\mathrm{ij}}^{\mathrm{kL}}, r_{\mathrm{ij}}^{\mathrm{kU}}\right], \ldots\left[\tilde{r}_{\mathrm{ij}}^{\mathrm{mL}}, \tilde{r}_{\mathrm{ij}}^{\mathrm{mU}}\right]\right\}
\end{aligned}
$$

where $\tilde{r}_{i j}^{k L}$ and $\tilde{r}_{i j}^{k U}$ are lower limit and upper limit, respectively.

Then an average rough number $\overline{\mathrm{RN}\left(\tilde{\mathrm{r}}_{i j}\right)}=\left[r_{i j}^{L}, r_{i j}^{U}\right]$ can be calculated by Eqs. (8-9),

$$
\begin{aligned}
& r_{\mathrm{ij}}^{L}=\left(\sum_{k=1}^{m} r_{\mathrm{ij}}^{\mathrm{kL}}\right) / m \\
& r_{\mathrm{ij}}^{U}=\left(\sum_{k=1}^{m} r_{\mathrm{ij}}^{\mathrm{kU}}\right) / m
\end{aligned}
$$

Here $r_{i j}^{L}$ and $r_{i j}^{U}$ are lower limit and upper limit of rough number, $\mathrm{m}$ is the number of decision makers.

After transforming the ratings into rough number, group rough direct-relation matrix for the strategies is established as Eq. (10).

$$
\begin{aligned}
G_{r} & =\left[\overline{\operatorname{RN}\left(\tilde{r}_{\mathrm{ij}}\right)}\right]_{n \times n} \\
& =\left[\begin{array}{cccc}
{[1,1]} & {\left[r_{12}^{L}, r_{12}^{U}\right]} & \ldots & {\left[r_{1 n}^{L}, r_{1 n}^{U}\right]} \\
{\left[r_{21}^{L}, r_{21}^{U}\right]} & {[1,1]} & \cdots & r_{2 n}^{k} \\
\vdots & \vdots & \ddots & \vdots \\
{\left[r_{n 1}^{L}, r_{n 1}^{U}\right]} & {\left[r_{n 2}^{L}, r_{n 2}^{U}\right]} & \cdots & {[1,1]}
\end{array}\right]
\end{aligned}
$$

\section{Construction of the Rough Total-Relation Matrix}

The linear scale transformation is used as a normalization formula to transform the scales of strategies into comparable scales. The constructed group rough direct-relation matrix $G_{r}$ can be normalized to obtain the matrix $G_{r}$ ' as Eq. (11).

$$
\begin{aligned}
G_{r}^{\prime} & =\left[\overline{\mathrm{RN}\left(\tilde{r}_{\mathrm{ij}}\right)^{\prime}}\right]_{n \times n} \\
& =\left[\begin{array}{cccc}
\overline{\mathrm{RN}\left(\tilde{r}_{11}\right)^{\prime}} & \overline{\mathrm{RN}\left(\tilde{r}_{12}\right)^{\prime}} & \ldots & \overline{\mathrm{RN}\left(\tilde{r}_{1 n}\right)^{\prime}} \\
\frac{\mathrm{RN}\left(\tilde{r}_{21}\right)^{\prime}}{\mathrm{RN}\left(\tilde{r}_{22}\right)^{\prime}} & \ldots & \overline{\mathrm{RN}\left(\tilde{r}_{2 n}\right)^{\prime}} \\
\frac{\vdots}{\mathrm{RN}\left(\tilde{r}_{n 1}\right)^{\prime}} & \frac{\vdots}{\mathrm{RN}\left(\tilde{r}_{n 2}\right)^{\prime}} & \ldots & \frac{\vdots}{\mathrm{RN}\left(\tilde{r}_{n n}\right)^{\prime}}
\end{array}\right]
\end{aligned}
$$

Here,

$\overline{\operatorname{RN}\left(\widetilde{r}_{\mathrm{ij}}\right)^{\prime}}=\frac{\overline{\mathrm{RN}\left(\widetilde{r}_{\mathrm{ij}}\right)}}{Z}=\left[\frac{r_{\mathrm{ij}}^{L}}{Z}, \frac{r_{\mathrm{ij}}^{U}}{Z}\right]$

$Z=\max _{1 \leq i \leq n}\left(\sum_{j=1}^{n} r_{\mathrm{ij}}^{U}\right)$

The group rough total-relation matrix $\mathrm{T}$ for the strategies can be acquired as follows.

$\mathrm{T}=\left[t_{i j}\right]_{n \times n}$

$t_{i j}=\left[t_{i j}^{L}, t_{i j}^{U}\right]$

$\mathrm{T}^{\varnothing}=\left[t_{i j}{ }^{\varnothing}\right]_{n \times n}=G_{r}{ }^{\prime \varnothing}\left(I-G_{r}{ }^{\prime \varnothing}\right)^{-1}, \varnothing=(L, U)$

where $t_{i j}^{L}$ and $t_{i j}^{U}$ are the lower limit and upper limit of rough interval $t_{i j}$ and $\mathrm{I}$ is the identity matrix.

Attain Rough Sum of Rows and Rough Sum of Columns for Strategies

For the group rough total-relation matrix, the rough sum of rows and rough sum of columns are denoted as $S_{i}$ and $C_{j}$, respectively,

$\left\{\begin{array}{c}S_{i}=\left[s_{i}^{L}, s_{i}^{U}\right]=\left[\sum_{j=1}^{n} t_{i j}^{L}, \sum_{j=1}^{n} t_{i j}^{U}\right] \\ C_{j}=\left[c_{j}^{L}, c_{j}^{U}\right]=\left[\sum_{i=1}^{n} t_{i j}^{L}, \sum_{i=1}^{n} t_{i j}^{U}\right]\end{array}\right.$

Calculation of Rough-Prominence and Rough-Relation for Strategies

Here, $\tilde{\mathbf{M}}_{i}$ and $\tilde{\mathbf{N}}_{i}$ represent total sum of $i^{\text {th }}$ row and $j^{\text {th }}$ column, respectively. $i^{\text {th }}$ row illustrates causal influence, whereas $j^{\text {th }}$ column illustrates effective influence. The value of $\tilde{\mathrm{M}}_{i}$ indicates how much importance specific strategy holds. If the value of $\tilde{\mathrm{M}}_{i}$ is larger, it means the degree of relation of each strategy is greater in relation to other strategy. $\tilde{\mathrm{N}}_{i}$ differentiates the strategies into cause and effect groups. When $\tilde{\mathrm{N}}_{i}$ is positive, the strategies are in the cause group. But if $\underset{\mathbf{N}}{\widetilde{N}_{i}}$ is negative, the strategies fall into the effect group. $\tilde{\mathrm{M}}_{i}$ is named as 'rough-prominence' and $\tilde{\mathbf{N}}_{i}$ is named as 'rough-relation'. 
$\left\{\begin{array}{l}\tilde{M}_{i}=S_{i}+C_{i}=\left[s_{i}^{L}+c_{i}^{L}, s_{i}^{U}+c_{i}^{U}\right] \\ \tilde{N}_{i}=S_{i}-C_{i}=\left\lceil s_{i}^{L}-c_{i}^{L}, s_{i}^{U}-c_{i}^{U}\right\rceil\end{array}\right.$

Formulate Prioritization of Flexible Strategies by Average Vector Length

Rough-prominence and rough-relation are obtained to achieve importance weights of strategies that will help to distinguish the most essential strategy. Figure 6 illustrates how to obtain four vector lengths starting from origin to each vertex of rough dataset $\left[\tilde{\mathrm{M}}_{i}, \tilde{\mathrm{N}}_{i}\right]$.

The greater weight for a strategy indicates how influential it is related to other strategies. To prioritize strategies, the average vector length (AVL), $L_{i}$ and importance weight, $W_{i}$ of $i^{\text {th }}$ strategies are calculated by following Eq. (19).

$$
\left\{\begin{array}{r}
L_{i}=\frac{\sqrt{\left(x^{L}\right)^{2}+\left(y^{L}\right)^{2}}+\sqrt{\left(x^{L}\right)^{2}+\left(y^{U}\right)^{2}}+\sqrt{\left(x^{U}\right)^{2}+\left(y^{L}\right)^{2}}+\sqrt{\left(x^{U}\right)^{2}+\left(y^{U}\right)^{2}}}{4} \quad W_{i}=L_{i} / \sum_{i=1}^{n} L_{i}
\end{array}\right.
$$

\section{Results}

Twelve of the 19 flexible strategies, identified through Pareto analysis and relevant challenges that can be tackled by each flexible strategy are determined on the basis of stakeholders' score, are presented in Table 5 and details are given in Appendix 2. To initiate revised rough-DEMATEL method, a team comprising of an associate professor of a renowned public university, a member of the governing body of a private educational institution, and an undergraduate student of a private university feedbacked in this stage to rate the strategies according to their impact on functionality of the education sector during the COVID-19 pandemic. A group direct-relation matrix is constructed based on stakeholders' ratings as shown in Table 9 (Appendix 1). As the matrix has been built on the basis of stakeholders' opinions, to remove vagueness and add much more precision, they are converted into rough numbers by following Eqs. (3-6) (see Table 10 in Appendix 1). After the values are obtained for both lower and higher estimations, they are normalized by Eq. (11) to adjust the values of numeric columns in the dataset to a standard scale and to get all variables to the same range. The normalized value for the lower approximation is shown in Table 11 (Appendix 1), while Table 12 (Appendix 1) reflects the normalized value for the higher approximation. As the normalized values are achieved, Table 6 is constructed by following Eq. (17), including both the lower and higher estimations for rough sum of row and rough sum of column. The obtained data set is used to determine roughprominence and rough-relationship matrix using Eq. (18), (as shown in Table 7) since they are being used to generate average vector length.

\section{Discussion of the Results}

The revised rough-DEMATEL method featuring AVL is used to classify the defined strategies according to their impact on the education sector. Table 7 presents roughprominence and rough-relation on the basis of the rough row and column sums.

From the obtained data sets from Table 7, the AVL is formulated by Eq. (19) to prioritize strategies accordingly. As the value of a specific strategy's rough-prominence and rough-relation is illustrated in a graph, it can capture fourvector lengths starting from origin to each rough dataset vertex. In Fig. 7, as an example, FS6, FS1, and FS12 are three strategies plotted.

To measure a strategy's weight, the average vector length for a particular strategy is used. The weight values as shown in Table 8 demonstrates how predominant a strategy is relative to other strategies. FS6, according to predominance, has the highest weight value, which puts the strategy at the very top of the rank. In contrast, the lowest rank is attained by FS12.
Fig. 6 Four vector lengths for flexible strategies

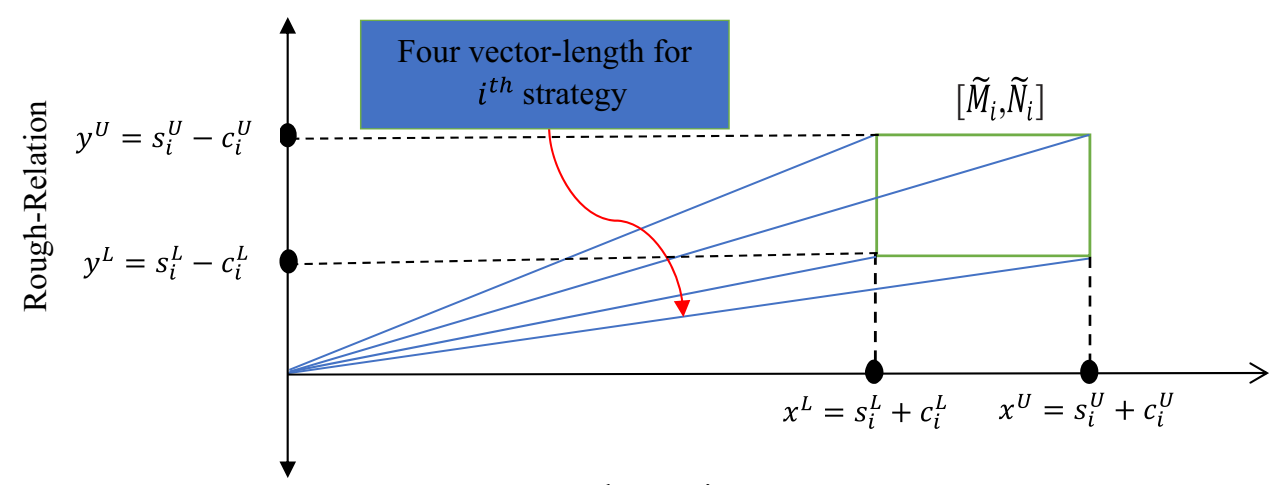

Rough-Prominence 
Table 5 Selected most influential flexible strategies to overcome challenges

\begin{tabular}{lll}
\hline Code & Flexible strategies & Effective for minimizing challenges \\
\hline FS1 & Know how to engage students in an online environment & $\mathrm{C} 1, \mathrm{C} 4, \mathrm{C} 5, \mathrm{C} 10, \mathrm{C} 13, \mathrm{C} 14$ \\
FS2 & Restructuring through resilience and flexibility & $\mathrm{C} 4, \mathrm{C} 7$ \\
FS3 & Utilize modern technologies for digitizing the entire education system & $\mathrm{C} 2, \mathrm{C} 4, \mathrm{C} 5, \mathrm{C} 10, \mathrm{C} 16$ \\
FS4 & Appropriate mechanisms of student assessment & $\mathrm{C} 10, \mathrm{C} 12$ \\
FS5 & Curriculum design framework for online learning & $\mathrm{C} 1, \mathrm{C} 4, \mathrm{C} 10, \mathrm{C} 12$ \\
FS6 & Maintain social distancing and health protocol & $\mathrm{C} 2, \mathrm{C} 3, \mathrm{C} 4, \mathrm{C} 10, \mathrm{C} 11, \mathrm{C} 16$ \\
FS7 & Enhance the communication and collaboration among students and teachers & $\mathrm{C} 2, \mathrm{C} 4, \mathrm{C} 10, \mathrm{C} 12, \mathrm{C} 14, \mathrm{C} 16$ \\
FS8 & Develop a communications plan between the faculties and administration & $\mathrm{C} 2, \mathrm{C} 4, \mathrm{C} 6, \mathrm{C} 11$ \\
FS9 & Ensure financial support for the most vulnerable students and families & $\mathrm{C} 3, \mathrm{C} 8, \mathrm{C} 9, \mathrm{C} 13$ \\
FS10 & Guidance about the safe use of screen time and online tools & $\mathrm{C} 5, \mathrm{C} 14, \mathrm{C} 15$, \\
FS11 & Financial incentives from government & $\mathrm{C} 3, \mathrm{C} 7, \mathrm{C} 8, \mathrm{C} 9, \mathrm{C} 13$ \\
FS12 & Enhancing teacher intrinsic motivation & $\mathrm{C} 4, \mathrm{C} 5, \mathrm{C} 11, \mathrm{C} 15$ \\
\hline
\end{tabular}

\section{Significance of the Key Findings}

In this section, the significance of investigating challenges of education sectors and flexible strategies to overcome those challenges amid the COVID-19 pandemic are discussed. The broader goal is to help educational institutions identify significant steps during the fight against COVID19 outbreak.

As COVID-19 is an infectious disease and spreading through social interactions, the education sector needs to be enhanced by social distancing and maintaining health protocol. This is the key reason why FS6: 'Maintain social distancing and health protocol' obtained the first ranking in overcoming the challenges in the education sector and was determined to be the most impactful strategy which helps to combat six vital challenges: $\mathrm{C} 2$ : 'Absence of online learning facilities,' C3: 'Chaotic learning environment at home,' C4: 'Inadequate preparedness of institutions and teachers,' C10: 'Lack in practical training,' C11: 'Fear of knowledge gap among future instructors,' and C16: 'Loss of direct interaction with both peers and teachers.' The pandemic has produced one of the largest interruptions in the history of educational systems, and these disruptions have gone beyond education and impacted many other sectors. The COVID-19 outbreak is a significant global public health issue that can threaten environmental as well as social sustainability and the quality of life of individuals (Severo et al. 2020). Therefore, ensuring social distance and obeying health precautions is necessary to minimize the spread of coronavirus. The number of infected patients

Table 6 Rough sum of row and column

\begin{tabular}{lllll}
\hline Strategy & $S_{L}$ & $C_{L}$ & $S_{U}$ & $C_{U}$ \\
\hline FS1 & 2.3951 & 2.4694 & 4.3567 & 4.4648 \\
FS2 & 2.1387 & 2.2709 & 3.9285 & 4.2683 \\
FS3 & 2.3270 & 2.5238 & 4.3658 & 4.6106 \\
FS4 & 1.8233 & 1.9952 & 3.5168 & 3.7628 \\
FS5 & 2.3367 & 2.3442 & 4.3658 & 4.3962 \\
FS6 & 2.6707 & 2.5934 & 4.8930 & 4.7226 \\
FS7 & 2.8021 & 2.3886 & 5.0944 & 4.4578 \\
FS8 & 1.7139 & 2.1147 & 3.3568 & 3.9140 \\
FS9 & 2.2856 & 2.0518 & 4.3959 & 3.8588 \\
FS10 & 2.2753 & 2.0463 & 4.0767 & 3.9164 \\
FS11 & 2.6134 & 1.9661 & 4.7443 & 3.4177 \\
FS12 & 1.7685 & & 3.5154 & 3.8200 \\
\hline
\end{tabular}


Table 7 Rough-prominence and rough-relation matrix

\begin{tabular}{|c|c|c|c|c|c|}
\hline \multirow[b]{2}{*}{ Strategy } & \multicolumn{2}{|c|}{ Rough-prominence } & \multicolumn{3}{|c|}{ Rough-relation } \\
\hline & $x^{L}=S_{L}+C_{L}$ & $x^{U}=S_{U}+C_{U}$ & $y^{L}=S_{L}-C_{L}$ & $y^{U}=S_{U}-C_{U}$ & Category \\
\hline FS1 & 4.8645 & 8.8215 & -0.0743 & -0.1081 & Effect group \\
\hline $\mathrm{FS} 2$ & 4.4096 & 8.1968 & -0.1322 & -0.3398 & Effect group \\
\hline FS3 & 4.8509 & 8.9765 & -0.1968 & -0.2448 & Effect group \\
\hline FS4 & 3.8184 & 7.2795 & -0.1719 & -0.2460 & Effect group \\
\hline FS5 & 4.6809 & 8.7620 & -0.0075 & -0.0305 & Effect group \\
\hline FS6 & 5.2640 & 9.6155 & 0.0773 & 0.1704 & Cause group \\
\hline FS7 & 5.1907 & 9.5522 & 0.4134 & 0.6365 & Cause group \\
\hline FS8 & 3.8286 & 7.2709 & -0.4009 & -0.5572 & Effect group \\
\hline FS9 & 4.3374 & 8.2547 & 0.2338 & 0.5371 & Cause group \\
\hline FS10 & 4.3216 & 7.9932 & 0.2290 & 0.1603 & Cause group \\
\hline FS11 & 4.9992 & 9.1620 & 0.2275 & 0.3267 & Cause group \\
\hline FS12 & 3.7346 & 7.3355 & -0.1976 & -0.3046 & Effect group \\
\hline
\end{tabular}

Fig. 7 Four vector lengths for flexible strategies

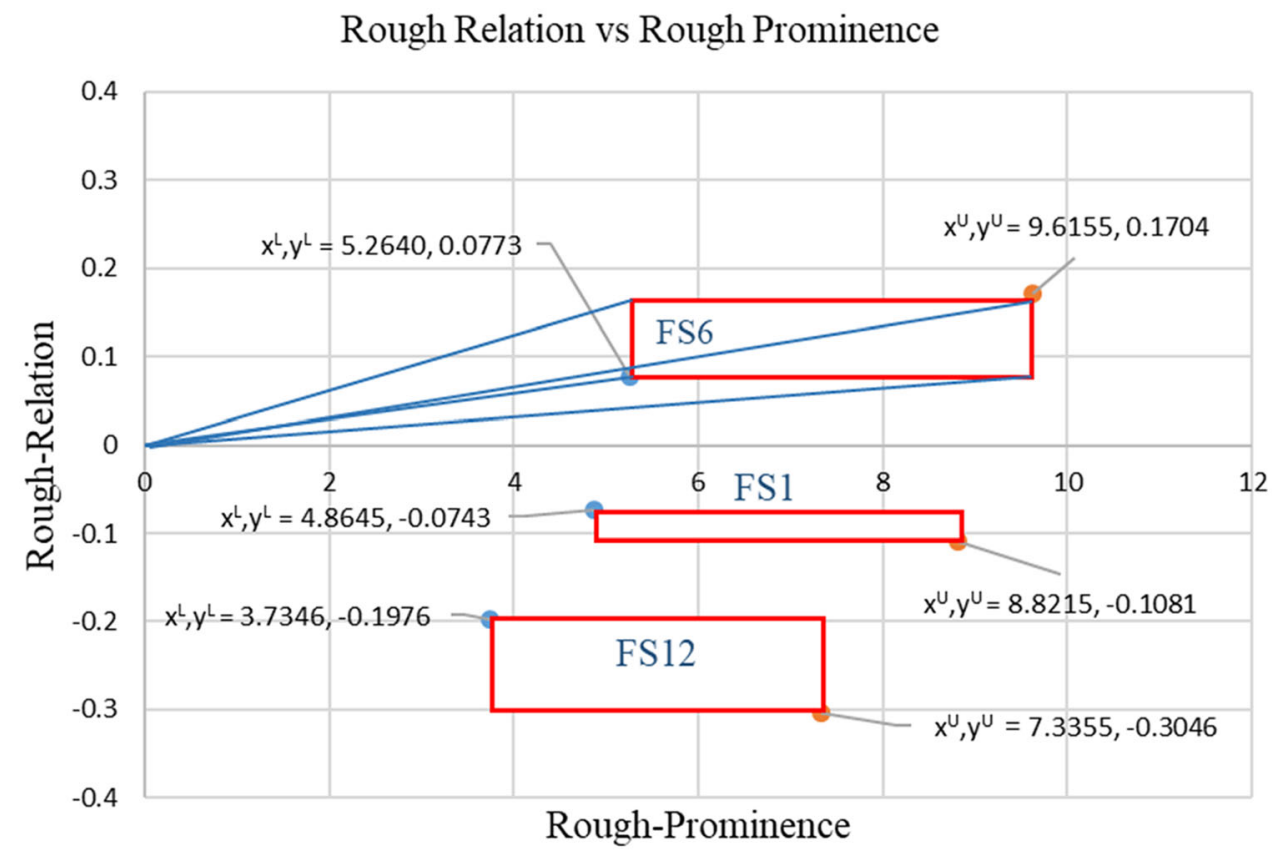

can increase if the regulations are compromised, which will cause every sector, including education, to remain stagnant.

The second highest weight value was obtained by FS7: 'Enhance the communication and collaboration among students and teachers' because it is important to create a cooperative relationship between educators and students, as distance learning and teaching needs to continue without any face-to-face contact. FS7 helps to overcome six more challenges: C2: 'Absence of online learning facilities,' C4: 'Inadequate preparedness of institutions and teachers,' C10: 'Lack in practical teaching,' C12: 'Ensuring quality assessments,' C14: 'Emotional discomfort and anxiety,' and C16: 'Loss of direct interactions with peers.' In order to connect with the faculty and students, institutions need to ensure consistent and relevant communication by an organized communication strategy for the continuity of learning (Sebastian and Nikol 2020).

Since the education sector, like many other sectors, is also affected by the current pandemic situation, FS11: 'Financial incentives from government' is also of greater significance in the implementation of a new framework. Educational institutions can take initiatives to ensure 
Table 8 Prioritization of flexible strategies by AVL

\begin{tabular}{llll}
\hline Strategy & AVL & Weight & Rank \\
\hline FS6 & 7.4411 & 0.02389 & 1 \\
FS7 & 7.3928 & 0.02374 & 2 \\
FS11 & 7.0867 & 0.02276 & 3 \\
FS3 & 6.9176 & 0.02221 & 4 \\
FS1 & 6.8436 & 0.02198 & 5 \\
FS5 & 6.7215 & 0.02158 & 6 \\
FS9 & 6.3111 & 0.02027 & 7 \\
FS2 & 6.3090 & 0.02026 & 8 \\
FS10 & 6.1609 & 0.01978 & 9 \\
FS8 & 5.5731 & 0.01790 & 10 \\
FS4 & 5.5535 & 0.01783 & 11 \\
FS12 & 5.5417 & 0.01780 & 12 \\
\hline
\end{tabular}

sustainability practices with the assistance of government policies and funds (Shuqin et al. 2019). As the pandemic situation has hit the globe, lower-income people have been massively impacted. During the long-term closing of national educational institution, a huge portion of vulnerable students require special attention (Drane et al. 2020). Thus, FS11 is an effective strategy in minimizing challenges like C3: 'Chaotic learning environment at home,' C7: 'Lack of development budget and investments from institutions,' C8: 'Poor socio-economic conditions of the citizens,' C9: 'Lack of government and international support,' and C13: 'Turning away from learning.'

FS3: 'Utilize modern technologies for digitizing the entire education system' strategy helps to restore education with proper measures during a pandemic situation if we digitalize the entire system (Evans et al. 2020). Developing a performance improvement and monitoring system can be possible with the help of science, modern technology, and innovation (Surana et al. 2020). Technologies, training programs, and expertise are required to digitize the education system (Romprasert and Monjagapate 2020). Furthermore, C2: 'Absence of online learning facilities,' C4: 'Inadequate preparedness of institutions and teachers,' C5: 'Institutional practices for using digital technologies effectively,' C10: 'Lack in practical teaching,' and C16: 'Loss of direct interactions with peers': these five challenges can be mitigated by deploying strategy FS3 .

Subsequently, implementation of FS1: 'Know how to engage students in an online environment' ensures adequate participation of students in the online-based education system and overcomes challenges such as $\mathrm{C} 1$ : 'Lack of instructional design,' C4: 'Inadequate preparedness of institutions and teachers,' C5: 'Institutional practices for using digital technologies effectively,' C10: 'Lack in practical teaching,' C13: 'Turning away from learning,' and C14: 'Emotional discomfort and anxiety.' These measures ensure participation of students in the onlinebased distance teaching system. As the current situation is not familiar to people, the challenges are many and tough to overcome. Effective implementation of the flexible strategies described can tackle the challenges and reduce the impact of challenges on the education sector. Since education will have to proceed through E-learning, it may be intimidating for many students to adapt to the new atmosphere. Thus, students and teachers need to build a much more engaged relationship that makes students feel comfortable with online learning to achieve maximum interaction. Moreover, teachers should build the framework and determine how they can apply it to their online course outlines to ensure a student-centered classroom (Tabor 2020).

\section{Results Validation}

A visual representation of the most crucial strategies and their interconnection with each other is the causal relationship diagram. In the graph, the values of roughprominence and rough-relation are projected to provide a clear view of strategies, their importance to the education sector, and their comparative effect. Figures 8 and 9 represent the causal relationship diagram for both the lower and higher estimations, respectively.

The values of $x^{L}$ and $x^{U}$ include rough-prominence that demonstrates how vital that particular strategy is in comparison to other strategies, whereas $y^{L}$ and $y^{U}$ provide the rough-relation between the strategies. The obtained strategies are further differentiated into a cause and effect group as shown in Table 7. According to the data set $y^{L}=$ $S_{L^{-}} C_{L}$ and $y^{U}=S_{U^{-}} C_{U}$ (both lower and higher estimations) FS6, FS7, FS9, FS10, and FS11 are grouped into cause group as these strategies have a positive net effect. To minimize the effect on the education sector, these cause groups' strategies are very relevant as they affect other parameters. The effect group reflects strategies that have negative net effect and are affected by the cause group. This group includes FS1, FS2, FS3, FS4, FS5, FS8, and FS12.

As the flexible strategies are presented based on their impact $S_{i}$ (for both lower and higher limit), a clear picture of flexible strategies with the most impactful strategies can be found from Table 6. It is very clear that FS6 has the most significant impact. And in this pandemic situation, it is crucial to keep all individuals oriented with the education sector safe and secure to continue their education. Table 6 also depicts that, FS7 and FS11 also have a noticeable impact. In contrast, FS8 has the least impact. 

diagram (lower estimation)
Fig. 8 Causal relationship

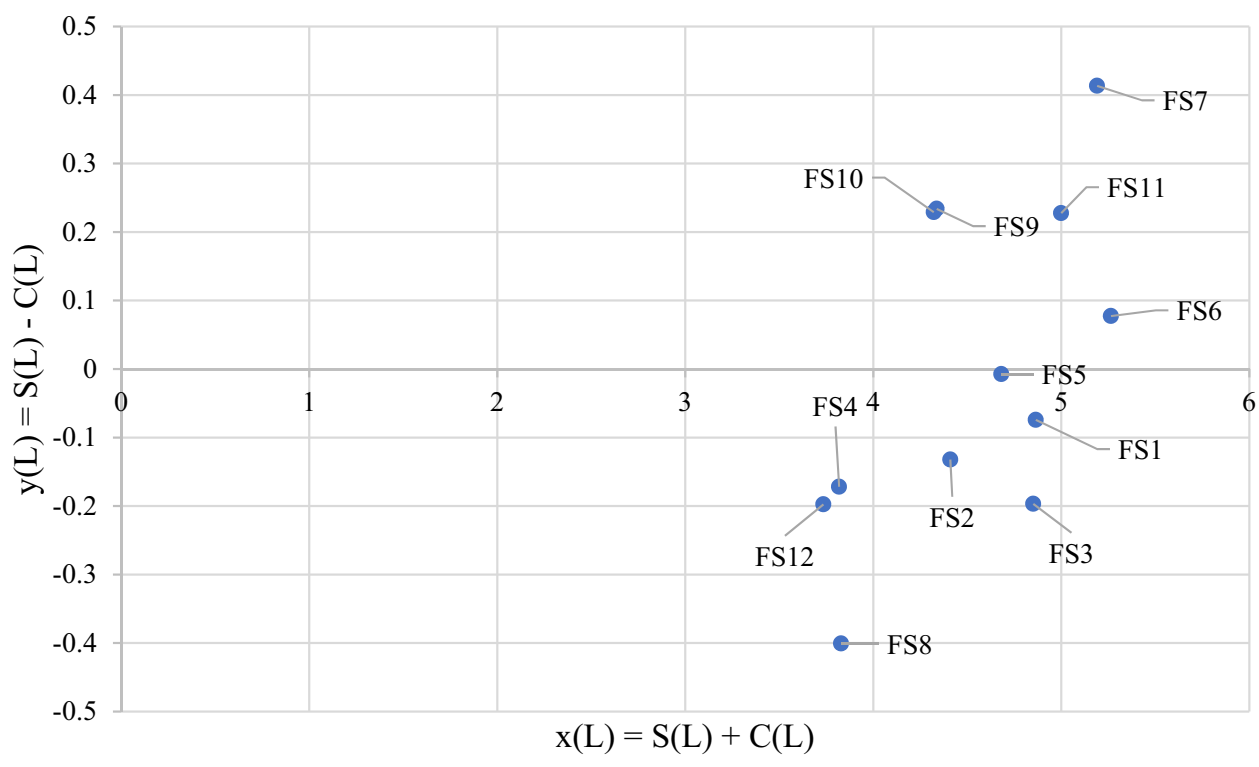

Fig. 9 Causal relationship diagram (higher estimation)

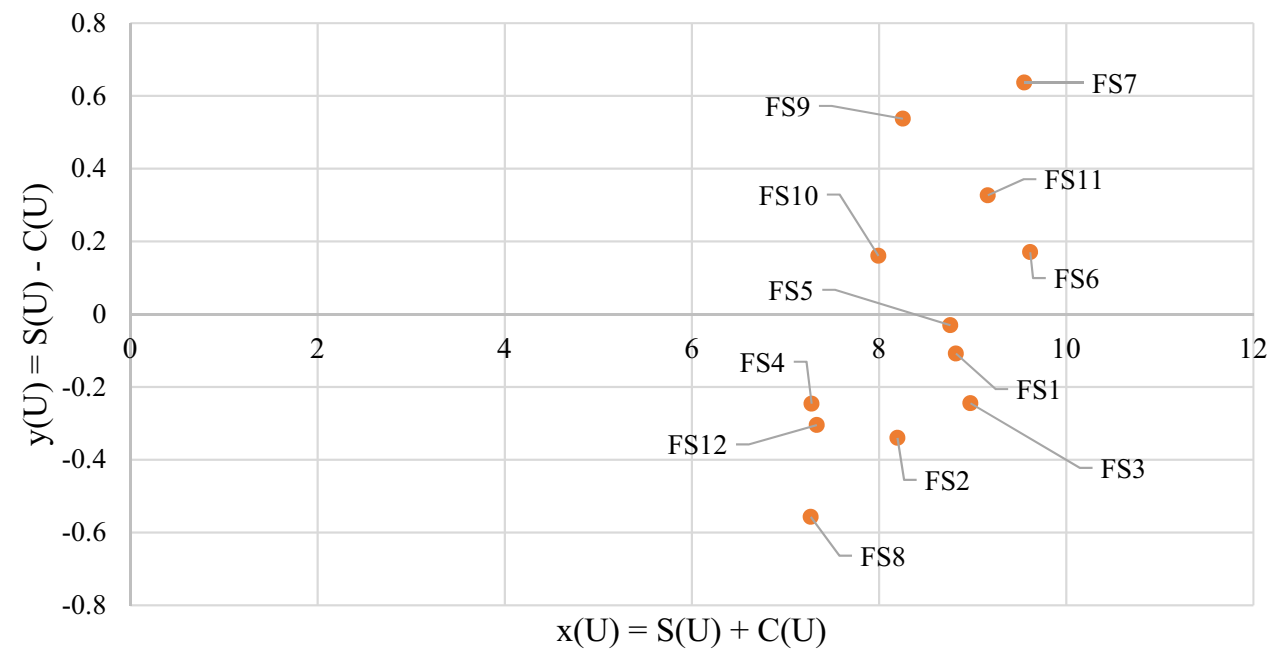

Furthermore, according to the rank acquired by $S_{i}+C_{i}$ score and AVL method Tables 7 and 8 represent FS6, FS7, FS11, FS3, and FS1 are the most effective strategies listed for overcoming challenges in the education sector. The strategy with higher $S_{i}+C_{i}$ score has optimum interaction with other strategies. In this ongoing pandemic situation, the first thing that needs to be ensured is social distancing and following proper health protocol to set things in motion again. This is why FS6 has the most vital link with other strategies. Since these five strategies constitute much of the weight value that is comparatively closer to each other, they are considered to be most pivotal in overcoming educational sector challenges.

\section{Implication of This Study}

\section{Implications to Theory}

COVID-19 has created a massive social disruption and has become a career shock for several students and instructors. Previous studies have recognized benefits of smaller class size in students learning (McKee et al. 2015), influence of E-learning on students' participation (Luo et al. 2017), importance of entrepreneurship education in management education during COVID-19 crisis (Ratten and Jones 2020), readiness and adaptation of the education sector for the $4^{\text {th }}$ industrial revolution (Oke and Fernandes 2020). The present study has identified the impacts of COVID-19 outbreak on the education sector and evaluated the flexible strategies to successfully continue the education processes amid the COVID-19 pandemic using an exhaustive 
literature review and stakeholders' opinions. In the context of the COVID-19 pandemic, it is important to find new avenues for education to work through this pandemic situation. Internet-based technology and platforms can play a key role in the conversion of education to digital learning platforms. Since social distance is a must and there can be no practical and face-to-face opportunities for teaching and learning, this study has contributed to literature by finding that enhancing communication between students and teachers, using digital platforms and other strategies can be key for continuing education and breaking through conventional teaching and learning process. Furthermore, another contribution of this study is the use of revised rough DEMATEL method to rank the strategies to prevent potential challenges, which thereby ensures resilience for sustainable education. Previously, Ranjan et al., (2015) and Çelikbilek and Adıgüzel Tüylü, (2019) have concentrated on evaluating performance of students implementing DEMATEL and prioritizing components of E-learning deploying fuzzy DEMATEL, respectively. However, the integrated Pareto-revised rough DEMATEL analysis used in this study not only reveals the significances of the strategies but also provides the interactions among the strategies. Finally, recommendations for government policymakers are provided to continue education related activities during the COVID-19 pandemic.

\section{Implications to Practice}

In the context of the COVID-19 outbreak, identifying challenges and flexible strategies to counter those challenges is crucial to prioritize the most impactful strategies to be implemented in the education sector. Based on the discussion included in this research, the twelve most effective strategies are defined to neutralize the effect of the COVID-19 pandemic considering social sustainability and resilience in education sector. The education system is striving to find new ways of restoring education because of the social distancing criteria and changing economic conditions. The significance of introducing E-learning is growing as education cannot proceed through face-to-face contact. But certain challenges need to be addressed to incorporate a system that is not accustomed to most individuals. It is not possible to avoid the COVID-19 crisis entirely, and it will take time to tackle it, which implies restoring economic and social stability are prime concerns to ensure resilience (Ratten and Jones 2020). To flatten the infection curve and reduce total fatalities, policymakers are recommended to implement the proposed strategies to restore social sustainability and build a way to adapt to the new standard by maintaining social distancing and health protocol. Like all other fields, to continue education, the education sector also needs to implement a new framework by reviewing and updating courseware content. The new framework needs to be designed to maintain resilience, bearing in mind that education cannot continue through face-to-face interaction due to social distance restrictions. Moreover, stakeholders should give concentration on the convenient understanding and cooperative participation of students with teachers, as education will be conducted online (Kaur et al. 2015).

Since many working people have been affected by the closure of everything, students from lower income families are now confronted with the dilemma of whether to continue education or start to work and earn for the family. In the context of COVID-19, many students may drop out of education simply because of economic challenges. It is crucial to prevent students from falling out in order to maintain sustainability in society. In this current situation, the government's financial incentives for internet connection, bandwidth and smart devices are vital to ensure both social and economic sustainability. The creation, execution, and monitoring of flexible overcoming techniques are crucial to success. Effective coordination, accountability, support, funding and timing are important for success (Loxton et al. 2013; Bondzi-Simpson and Agomor 2020). Government policymakers are recommended to provide support and assistance for digitizing the entire education system to engage students in an online environment through the utilization of modern technologies. The findings of this study will assist government policymakers, students, and educators to have an understanding of the strategies for emergency distance learning arrangements.

Finally, educational stakeholders and government policymakers in developed and developing countries find this research useful to take appropriate decisions on flexible strategies in academic sectors during this crisis period. Thus, the findings may guide them in creating government policies and funds, enhancing institutionalized approaches, incorporating health and safety initiatives, ensuring teaching and learning activities during this crisis time for adopting SDGs in educational institutions.

\section{Conclusions}

The disturbances that have occurred in education due to COVID-19 outbreak ought to be carefully handled. Both the opening and the closures of institutions may generate risks such as economic, health, social, mental, and behavioral changes for students. To help them overcome and achieve SDGs, possible challenges, adopting and developing new techniques for dealing with emerging and dynamic environments are necessary.

This research blends the rough set principle and the DEMATEL method for identification and prioritization of 
flexible strategies along with causal and impact relationships between strategies to handle the challenges. This study effectively evolves DEMATEL in an unpredictable setting through using the rough intervals that represent the arbitrary and unclear decisions of policy makers. In addition, the methodology presented can detect changes in judgment in the decision-making assessment of flexible strategies.

This study explains the difficulties faced by different education institutions of emerging economies like Bangladesh that rely on distance learning during this crisis time. The outcome of this research helps to assess and enforce the most appropriate approach for the education system in the context of the COVID-19 pandemic. From this paper, educators and educational leaders can draw useful suggestions to preserve the resilience of education sector and attain flexibility as well as SDGs in low- and medium-income countries.
While the suggested analytical approach has proven effective for ranking the flexible strategies to manage the COVID-19 pandemic, in future research, fuzzy DEMATEL and grey DEMATEL techniques could be applied using more sample size, and the results from these methods can validate the findings of this research. Future researchers can also consider costs for implementing different flexible strategies and model the studied problem using optimization techniques.

\section{Declaration}

Conflict of interest The authors declare that they have no known competing financial interests or personal relationships that could have appeared to influence the work reported in this paper.

\section{Appendix 1}

See Tables 9, 10, 11 and 12.

Table 9 Group initial direct relation matrix

\begin{tabular}{lllllllllllll}
\hline Strategy & FS1 & FS2 & FS3 & FS4 & FS5 & FS6 & FS7 & FS8 & FS9 & FS10 & FS11 & FS12 \\
\hline FS1 & $1,1,1$ & $4,3,3$ & $2,3,3$ & $3,2,2$ & $2,3,2$ & $2,2,2$ & $3,3,4$ & $2,3,2$ & $1,2,1$ & $2,2,2$ & $2,2,2$ & $1,2,1$ \\
FS2 & $3,3,3$ & $1,1,1$ & $2,3,2$ & $2,1,1$ & $2,3,2$ & $2,2,3$ & $3,3,3$ & $2,1,1$ & $2,2,2$ & $2,1,1$ & $2,2,1$ & $2,1,1$ \\
FS3 & $3,3,2$ & $2,2,2$ & $1,1,1$ & $2,3,2$ & $2,2,3$ & $2,1,2$ & $2,2,3$ & $3,2,2$ & $2,2,1$ & $3,3,4$ & $2,3,3$ & $1,1,2$ \\
FS4 & $2,2,2$ & $2,1,1$ & $2,3,3$ & $1,1,1$ & $2,2,1$ & $1,2,2$ & $2,2,1$ & $2,2,1$ & $1,1,1$ & $1,2,2$ & $2,3,2$ & $1,2,2$ \\
FS5 & $2,3,2$ & $3,2,3$ & $3,2,3$ & $2,2,2$ & $1,1,1$ & $1,2,2$ & $2,3,2$ & $3,3,2$ & $2,3,3$ & $2,3,2$ & $2,3,2$ & $1,1,2$ \\
FS6 & $4,3,4$ & $3,4,3$ & $3,3,2$ & $2,2,2$ & $2,3,2$ & $3,3,2$ & $1,1,1$ & $1,2,2$ & $2,3,2$ & $2,3,3$ & $2,2,3$ & $3,2,3$ \\
FS7 & $2,2,3$ & $3,2,2$ & $2,2,3$ & $2,3,2$ & $2,3,3$ & $1,1,1$ & $4,3,3$ & $3,3,3$ & $3,4,3$ & $2,2,3$ & $2,3,3$ & $3,4,3$ \\
FS8 & $1,2,2$ & $1,1,2$ & $1,1,1$ & $2,2,1$ & $2,1,2$ & $2,3,3$ & $1,2,2$ & $1,1,1$ & $1,1,1$ & $2,1,2$ & $2,2,1$ & $2,2,3$ \\
FS9 & $2,2,1$ & $2,3,3$ & $2,3,2$ & $1,2,1$ & $2,3,3$ & $3,3,4$ & $2,3,3$ & $1,1,2$ & $1,1,1$ & $1,1,2$ & $3,3,4$ & $1,1,2$ \\
FS10 & $2,2,2$ & $1,2,2$ & $3,4,4$ & $2,2,1$ & $3,3,3$ & $2,3,3$ & $2,2,2$ & $1,2,2$ & $1,2,1$ & $1,1,1$ & $2,2,2$ & $1,2,2$ \\
FS11 & $2,3,3$ & $2,1,2$ & $3,3,3$ & $2,3,3$ & $2,3,3$ & $3,2,3$ & $2,3,3$ & $2,2,2$ & $3,4,3$ & $1,2,2$ & $1,1,1$ & $2,3,3$ \\
FS12 & $1,2,2$ & $2,1,2$ & $1,1,2$ & $1,1,2$ & $1,2,1$ & $2,3,2$ & $3,2,2$ & $2,2,2$ & $1,1,2$ & $1,1,2$ & $2,3,2$ & $1,1,1$ \\
\hline
\end{tabular}

Table 10 Group rough-relation matrix

\begin{tabular}{lllllllllllll}
\hline Strategy & FS1 & FS2 & FS3 & FS4 & FS5 & FS6 & FS7 & FS8 & FS9 & FS10 & FS11 & FS12 \\
\hline FS1(L) & 1.000 & 3.111 & 2.444 & 2.111 & 2.111 & 2.000 & 3.111 & 2.111 & 1.111 & 2.000 & 2.000 & 1.111 \\
FS1(U) & 1.000 & 3.556 & 2.889 & 2.556 & 2.556 & 2.000 & 3.556 & 2.556 & 1.556 & 2.000 & 2.167 & 1.556 \\
FS2(L) & 3.000 & 1.000 & 2.111 & 1.111 & 2.111 & 2.111 & 3.000 & 1.111 & 2.000 & 1.111 & 1.444 & 1.111 \\
FS2(U) & 3.000 & 1.000 & 2.556 & 1.556 & 2.556 & 2.556 & 3.000 & 1.556 & 2.000 & 1.556 & 1.889 & 1.556 \\
FS3(L) & 2.444 & 2.000 & 1.000 & 2.111 & 2.111 & 1.444 & 2.111 & 2.222 & 1.444 & 3.111 & 2.444 & 1.111 \\
FS3(U) & 2.889 & 2.000 & 1.000 & 2.556 & 2.556 & 1.889 & 2.556 & 2.778 & 1.889 & 3.556 & 2.889 & 1.556 \\
FS4(L) & 2.000 & 1.111 & 2.444 & 1.000 & 1.444 & 1.444 & 1.444 & 1.444 & 1.000 & 1.444 & 2.111 & 1.444 \\
FS4(U) & 2.000 & 1.556 & 2.889 & 1.000 & 1.889 & 1.889 & 1.889 & 1.889 & 1.000 & 1.889 & 2.556 & 1.889 \\
FS5(L) & 2.111 & 2.444 & 2.444 & 2.000 & 1.000 & 1.444 & 2.111 & 2.444 & 2.444 & 2.111 & 2.111 & 1.111 \\
FS5(U) & 2.556 & 2.889 & 2.889 & 2.000 & 1.000 & 1.889 & 2.556 & 2.889 & 2.889 & 2.556 & 2.556 & 1.556 \\
FS6(L) & 3.444 & 3.111 & 2.444 & 2.000 & 2.111 & 2.444 & 1.000 & 1.444 & 2.111 & 2.444 & 2.111 & 2.444 \\
FS6(U) & 3.889 & 3.556 & 2.889 & 2.000 & 2.556 & 2.889 & 1.000 & 1.889 & 2.556 & 2.889 & 2.556 & 2.889 \\
\hline
\end{tabular}


Table 10 continued

\begin{tabular}{|c|c|c|c|c|c|c|c|c|c|c|c|c|}
\hline Strategy & FS1 & $\mathrm{FS} 2$ & FS3 & FS4 & FS5 & FS6 & FS7 & FS8 & FS9 & FS10 & FS11 & $\overline{\text { FS12 }}$ \\
\hline FS7(L) & 2.111 & 2.111 & 2.111 & 2.111 & 2.444 & 1.000 & 3.111 & 3.000 & 3.111 & 2.111 & 2.444 & 3.111 \\
\hline FS7(U) & 2.556 & 2.556 & 2.556 & 2.556 & 2.889 & 1.000 & 3.556 & 3.000 & 3.556 & 2.556 & 2.889 & 3.556 \\
\hline FS8(L) & 1.444 & 1.111 & 1.000 & 1.444 & 1.444 & 2.444 & 1.444 & 1.000 & 1.000 & 1.444 & 1.444 & 2.111 \\
\hline FS8(U) & 1.889 & 1.556 & 1.000 & 1.889 & 1.889 & 2.889 & 1.889 & 1.000 & 1.000 & 1.889 & 1.889 & 2.556 \\
\hline FS9(L) & 1.444 & 2.444 & 2.111 & 1.111 & 2.444 & 3.111 & 2.444 & 1.111 & 1.000 & 1.111 & 3.111 & 1.111 \\
\hline FS9(U) & 1.889 & 2.889 & 2.556 & 1.556 & 2.889 & 3.556 & 2.889 & 1.556 & 1.000 & 1.556 & 3.556 & 1.556 \\
\hline FS10(L) & 2.000 & 1.444 & 3.444 & 1.444 & 3.000 & 2.444 & 2.000 & 1.444 & 1.111 & 1.000 & 2.000 & 1.444 \\
\hline FS10(U) & 2.000 & 1.889 & 3.889 & 1.889 & 3.000 & 2.889 & 2.000 & 1.889 & 1.556 & 1.000 & 2.000 & 1.889 \\
\hline FS11(L) & 2.444 & 1.444 & 3.000 & 2.444 & 2.444 & 2.444 & 2.444 & 2.000 & 3.111 & 1.444 & 1.000 & 2.444 \\
\hline FS11(U) & 2.889 & 1.889 & 3.000 & 2.889 & 2.889 & 2.889 & 2.889 & 2.000 & 3.556 & 1.889 & 1.000 & 2.889 \\
\hline FS12(L) & 1.444 & 1.444 & 1.111 & 1.111 & 1.111 & 2.111 & 2.111 & 2.000 & 1.111 & 1.111 & 2.111 & 1.000 \\
\hline FS12(U) & 1.889 & 1.889 & 1.556 & 1.556 & 1.556 & 2.556 & 2.556 & 2.000 & 1.556 & 1.556 & 2.556 & 1.000 \\
\hline
\end{tabular}

Table 11 Group rough total-relation matrix (lower limit)

\begin{tabular}{llllllllllllll}
\hline Strategy & FS1 & FS2 & FS3 & FS4 & FS5 & FS6 & FS7 & FS8 & FS9 & FS10 & FS11 & FS12 & $S_{i}$ \\
\hline FS1 & 0.1853 & 0.2318 & 0.2283 & 0.1860 & 0.2073 & 0.2056 & 0.2509 & 0.1921 & 0.1608 & 0.1867 & 0.2050 & 0.1553 & 2.3951 \\
FS2 & 0.2257 & 0.1592 & 0.2020 & 0.1446 & 0.1923 & 0.1937 & 0.2324 & 0.1505 & 0.1734 & 0.1483 & 0.1752 & 0.1413 & 2.1387 \\
FS3 & 0.2204 & 0.1949 & 0.1834 & 0.1824 & 0.2039 & 0.1863 & 0.2172 & 0.1916 & 0.1654 & 0.2141 & 0.2138 & 0.1537 & 2.3270 \\
FS4 & 0.1752 & 0.1399 & 0.1906 & 0.1246 & 0.1530 & 0.1542 & 0.1647 & 0.1432 & 0.1263 & 0.1404 & 0.1741 & 0.1370 & 1.8233 \\
FS5 & 0.2115 & 0.2087 & 0.2241 & 0.1790 & 0.1716 & 0.1874 & 0.2182 & 0.1979 & 0.1948 & 0.1856 & 0.2057 & 0.1523 & 2.3367 \\
FS6 & 0.2708 & 0.2484 & 0.2461 & 0.1963 & 0.2241 & 0.2357 & 0.2105 & 0.1888 & 0.2032 & 0.2127 & 0.2262 & 0.2080 & 2.6707 \\
FS7 & 0.2399 & 0.2264 & 0.2430 & 0.2054 & 0.2401 & 0.2036 & 0.2771 & 0.2395 & 0.2385 & 0.2090 & 0.2443 & 0.2353 & 2.8021 \\
FS8 & 0.1513 & 0.1331 & 0.1408 & 0.1311 & 0.1459 & 0.1770 & 0.1577 & 0.1244 & 0.1213 & 0.1330 & 0.1482 & 0.1502 & 1.7139 \\
FS9 & 0.1910 & 0.2072 & 0.2121 & 0.1526 & 0.2113 & 0.2314 & 0.2266 & 0.1594 & 0.1558 & 0.1551 & 0.2318 & 0.1511 & 2.2856 \\
FS10 & 0.2049 & 0.1774 & 0.2490 & 0.1619 & 0.2257 & 0.2097 & 0.2113 & 0.1693 & 0.1552 & 0.1531 & 0.1992 & 0.1584 & 2.2753 \\
FS11 & 0.2374 & 0.1974 & 0.2566 & 0.2064 & 0.2291 & 0.2323 & 0.2462 & 0.2020 & 0.2289 & 0.1819 & 0.1921 & 0.2030 & 2.6134 \\
FS12 & 0.1560 & 0.1465 & 0.1477 & 0.1247 & 0.1400 & 0.1716 & 0.1806 & 0.1559 & 0.1283 & 0.1264 & 0.1703 & 0.1205 & 1.7685 \\
$C_{j}$ & 2.4694 & 2.2709 & 2.5238 & 1.9952 & 2.3442 & 2.3886 & 2.5934 & 2.1147 & 2.0518 & 2.0463 & 2.3859 & 1.9661 & \\
\hline
\end{tabular}

Table 12 Group rough total-relation matrix (higher limit)

\begin{tabular}{llllllllllllll}
\hline Strategy & FS1 & FS2 & FS3 & FS4 & FS5 & FS6 & FS7 & FS8 & FS9 & FS10 & FS11 & FS12 & $S_{i}$ \\
\hline FS1 & 0.3445 & 0.4016 & 0.4065 & 0.3374 & 0.3818 & 0.3699 & 0.4321 & 0.3478 & 0.3165 & 0.3340 & 0.3714 & 0.3131 & 4.3567 \\
FS2 & 0.3702 & 0.3016 & 0.3658 & 0.2840 & 0.3522 & 0.3544 & 0.3861 & 0.2939 & 0.3043 & 0.2947 & 0.3345 & 0.2868 & 3.9285 \\
FS3 & 0.3964 & 0.3576 & 0.3546 & 0.3386 & 0.3830 & 0.3680 & 0.4042 & 0.3548 & 0.3259 & 0.3771 & 0.3919 & 0.3136 & 4.3658 \\
FS4 & 0.3115 & 0.2863 & 0.3442 & 0.2432 & 0.3037 & 0.3062 & 0.3220 & 0.2775 & 0.2490 & 0.2782 & 0.3234 & 0.2716 & 3.5168 \\
FS5 & 0.3874 & 0.3827 & 0.4066 & 0.3219 & 0.3381 & 0.3685 & 0.4049 & 0.3570 & 0.3543 & 0.3486 & 0.3833 & 0.3126 & 4.3658 \\
FS6 & 0.4624 & 0.4388 & 0.4466 & 0.3542 & 0.4203 & 0.4330 & 0.4025 & 0.3631 & 0.3784 & 0.3908 & 0.4207 & 0.3821 & 4.8930 \\
FS7 & 0.4391 & 0.4236 & 0.4500 & 0.3805 & 0.4422 & 0.3950 & 0.4876 & 0.4053 & 0.4186 & 0.3934 & 0.4451 & 0.4142 & 5.0944 \\
FS8 & 0.2958 & 0.2759 & 0.2785 & 0.2584 & 0.2918 & 0.3236 & 0.3105 & 0.2410 & 0.2396 & 0.2660 & 0.2931 & 0.2824 & 3.3568 \\
FS9 & 0.3739 & 0.3867 & 0.4011 & 0.3132 & 0.3959 & 0.4171 & 0.4194 & 0.3236 & 0.3079 & 0.3241 & 0.4150 & 0.3179 & 4.3959 \\
FS10 & 0.3518 & 0.3348 & 0.4136 & 0.3029 & 0.3749 & 0.3735 & 0.3682 & 0.3139 & 0.3006 & 0.2887 & 0.3484 & 0.3052 & 4.0767 \\
FS11 & 0.4230 & 0.3817 & 0.4372 & 0.3696 & 0.4179 & 0.4224 & 0.4436 & 0.3566 & 0.3975 & 0.3538 & 0.3674 & 0.3735 & 4.7443 \\
FS12 & 0.3086 & 0.2969 & 0.3059 & 0.2588 & 0.2944 & 0.3263 & 0.3415 & 0.2794 & 0.2662 & 0.2670 & 0.3234 & 0.2470 & 3.5154 \\
$C_{j}$ & 4.4648 & 4.2683 & 4.6106 & 3.7628 & 4.3962 & 4.4578 & 4.7226 & 3.9140 & 3.8588 & 3.9164 & 4.4177 & 3.8200 & \\
\hline
\end{tabular}




\section{Appendix 2}

\section{Questionnaire}

Across the globe, the spread of novel coronavirus COVID19 has led to profound changes in social interaction and organization, and the education sector has not been immune. COVID-19 outbreak has affected all levels of the education system, from pre-school to tertiary education. For universities and colleges, this has meant the complete closure of campuses or at least a severe reduction in the number and type of face-to-face learning sessions offered to students. As a consequence, educators are rapidly adapting their learning provision by moving as much online as possible so that students can continue to learn and engage, albeit remotely. But there are lot of challenges to maintain the continuity of education. We point out some challenges and flexible strategies for education sectors amid the COVID-19 pandemic.

The purpose of this survey is to prioritize the strategies to overcome those challenges based on your feedback. Your response will be kept confidential and would be used strictly for research purposes. The survey should take no longer than $5 \mathrm{~min}$ to complete. We appreciate your support and thank you for your participation.

\section{Which of the following category describe your age?}

- Younger than 18

- $18-24$

- 25-34

- 35-44

- Older than 44

In terms of your current occupation, how would you characterize yourself?

- Teacher

- Student

- Other:

If you are a teacher, what is your current position? If not then select none.

- Lecturer
- Assistant Professor

- Associate Professor

- Professor

- None

Which flexible strategies under the category of "Initial framework building" will be most effective for mitigating challenges?

- Curriculum design framework for online learning

- Know how to engage students in an online environment

- Develop alternative means of delivery

- Maintain social distancing and health protocol

- Develop a plan for continuity of operations amid COVID-19

- Utilize modern technologies for digitizing the entire education system

Which flexible strategies under the category of "Planning and preparation" will be most effective for mitigating challenges?

- Appropriate mechanisms of student assessment

- Restructuring through resilience and flexibility

- Maintain social distancing and health protocol

- Utilize modern technologies for digitizing the entire education system

- Just in time professional development for teachers and parents

- Develop a plan for continuity of operations amid COVID-19

Which flexible strategies under the category of "Collaborative communication" will be most effective for mitigating challenges?

- Enhance the communication and collaboration among students and teachers

- Develop a communications plan between the faculties and administration

- Public-private partnership for education system development

- Enabling social learning connections with educators and their peers 
Which flexible strategies under the category of "Financial assistance, support, and guidance" will be most effective for mitigating challenges?

- Ensure financial support for the most vulnerable students and families

- Guidance about the safe use of screen time and online tools

- Financial incentives from government

- Enhancing teacher intrinsic motivation

- Promote active facilitation and learning support (including feedback)

- Expansion of welfare programs to provide mental support

\section{Which category amongst them will be most effective for mitigating challenges?}

- Initial framework building

- Planning and preparation

- Collaborative communication

- Financial assistance, support and guidance

\section{Please select relevant challenges that can be tackled by each flexible strategy (List of challenges and strategies with their codes is provided with this email).}

See Tables 13, 14, 15, and 16.

Table 13 Category A (Initial framework building)

\begin{tabular}{lll}
\hline Strategy Name & Frequency & Cum \% \\
\hline $\begin{array}{l}\text { Curriculum design framework for online } \\
\text { learning }\end{array}$ & 69 & $34.50 \%$ \\
$\begin{array}{l}\text { Know how to engage students in an online } \\
\text { environment }\end{array}$ & 51 & $60 \%$ \\
$\begin{array}{l}\text { Utilize modern technologies for digitizing the } \\
\text { entire education system }\end{array}$ & 34 & $77 \%$ \\
$\begin{array}{l}\text { Maintain social distancing and health protocol } \\
\text { Develop a plan for continuity of operations } \\
\text { amid COVID-19 }\end{array}$ & 17 & $85.50 \%$ \\
\begin{tabular}{l} 
Develop alternative means of delivery \\
\hline
\end{tabular} & 12 & $94 \%$ \\
\hline
\end{tabular}

Table 14 Category B (Planning and preparation)

\begin{tabular}{lll}
\hline Strategy Name & Frequency & $\begin{array}{l}\text { Cum } \\
\%\end{array}$ \\
\hline Appropriate mechanisms of student assessment & 86 & $43 \%$ \\
Restructuring through resilience and flexibility & 40 & $63 \%$ \\
Maintain social distancing and health protocol & 34 & $80 \%$ \\
Utilize modern technologies for digitizing the & 17 & $89 \%$ \\
$\quad$ entire education system & & \\
Just in time professional development for teachers & 17 & $97 \%$ \\
$\quad$ and parents & & \\
Develop a plan for continuity of operations amid & 6 & $100 \%$ \\
$\quad$ COVID-19 & \\
\hline
\end{tabular}

Table 15 Category C (Collaborative communication)

\begin{tabular}{lll}
\hline Strategy Name & Frequency & $\begin{array}{l}\text { Cum } \\
\%\end{array}$ \\
\hline $\begin{array}{l}\text { Enhance the communication and collaboration } \\
\text { among students and teachers }\end{array}$ & 86 & $43 \%$ \\
$\begin{array}{l}\text { Develop a communications plan between the } \\
\text { faculties and administration }\end{array}$ & 51 & $69 \%$ \\
$\begin{array}{l}\text { Public-private partnership for education system } \\
\text { development }\end{array}$ & 34 & $86 \%$ \\
$\begin{array}{l}\text { Enabling social learning connections with } \\
\text { educators and their peers }\end{array}$ & 29 & $100 \%$ \\
\hline
\end{tabular}

Table 16 Category D (Financial assistance, support and guidance)

\begin{tabular}{lll}
\hline Strategy Name & Frequency & $\begin{array}{l}\text { Cum } \\
\%\end{array}$ \\
\hline $\begin{array}{l}\text { Ensure financial support for the most vulnerable } \\
\text { students and families }\end{array}$ & 57 & $29 \%$ \\
$\begin{array}{l}\text { Guidance about the safe use of screen time and } \\
\text { online tools }\end{array}$ & 51 & $54 \%$ \\
$\begin{array}{l}\text { Financial incentives from government } \\
\text { Enhancing teacher intrinsic motivation }\end{array}$ & 41 & $75 \%$ \\
$\begin{array}{l}\text { Promote active facilitation and learning support } \\
\quad \text { (including feedback) }\end{array}$ & 11 & $92 \%$ \\
$\begin{array}{l}\text { Expansion of welfare programs to provide mental } \\
\text { support }\end{array}$ & 6 & $97 \%$ \\
\hline
\end{tabular}

\section{References}

Acharya, S. (2019). Beyond learning outcomes: Impact of organizational flexibility on strategic performance measures of commercial E-learning providers. Global Journal of Flexible Systems Management, 20(1), 31-41. https://doi.org/10.1007/s40171-0180199-3.

Adarkwah, M. A. (2020). "I'm not against online teaching, but what about us?": ICT in Ghana post Covid-19. Education and Information Technologies. https://doi.org/10.1007/s10639-02010331-z.

Alqahtani, A. Y., \& Rajkhan, A. A. (2020). E-learning critical success factors during the COVID-19 pandemic: A comprehensive analysis of E-learning managerial perspectives. Education Sciences, 10(9), 216. https://doi.org/10.3390/educsci10090216. 
Banik, A., Taqi, H. M. M., Ali, S. M., Ahmed, S., Garshasbi, M., \& Kabir, G. (2020). Critical success factors for implementing green supply chain management in the electronics industry: An emerging economy case. International Journal of Logistics Research and Applications. https://doi.org/10.1080/13675567. 2020.1839029.

Bao, W. (2020). COVID-19 and online teaching in higher education: A case study of Peking University. Human Behavior and Emerging Technologies, 2(2), 113-115. https://doi.org/10.1002/ hbe2.191.

Barteit, S., Guzek, D., Jahn, A., Bärnighausen, T., Jorge, M. M., \& Neuhann, F. (2020). Evaluation of e-learning for medical education in low-and middle-income countries: A systematic review. Computers and Education, 145, 103726. https://doi.org/ 10.1016/j.compedu.2019.103726.

Beteille, T., Ding, E., Molina, E., Pushparatnam, A., \& Wilichowski, T. (2020). Three principles to support teacher effectiveness during COVID-19. . World Bank.

Blundell, R., Costa Dias, M., Joyce, R., \& Xu, X. (2020). COVID-19 and inequalities*. Fiscal Studies, 41(2), 291-319. https://doi.org/ 10.1111/1475-5890.12232.

Bokde, V., Kharbikar, H. L., Roy, M. L., Joshi, P., \& Atheequlla, G. A. (2020). Possible impacts of COVID-19 pandemic and lockdown on education sector in India. Food and Scientific Reports, 1, 30-33.

Bondzi-Simpson, P. E., \& Agomor, K. S. (2020). Financing Public Universities in Ghana through strategic agility: Lessons from Ghana Institute of Management and Public Administration (GIMPA). Global Journal of Flexible Systems Management, 22, 1-15. https://doi.org/10.1007/s40171-020-00254-6.

Çelikbilek, Y., \& Adıgüzel Tüylü, A. N. (2019). Prioritizing the components of e-learning systems by using fuzzy DEMATEL and ANP. Interactive Learning Environments. https://doi.org/10. 1080/10494820.2019.1655065.

Chen, Z., Lu, M., Ming, X., Zhang, X., \& Zhou, T. (2020). Explore and evaluate innovative value propositions for smart product service system: A novel graphics-based rough-fuzzy DEMATEL method. Journal of Cleaner Production, 243, 118672. https://doi. org/10.1016/j.jclepro.2019.118672.

Chirra, S., \& Kumar, D. (2018). Evaluation of supply chain flexibility in automobile industry with fuzzy DEMATEL approach. Global Journal of Flexible Systems Management, 19(4), 305-319. https://doi.org/10.1007/s40171-018-0195-7.

Choudhury, S., \& Pattnaik, S. (2020). Emerging themes in e-learning: A review from the stakeholders' perspective. Computers and Education, 144, 103657. https://doi.org/10.1016/j.compedu. 2019.103657.

Christine, G., \& Amy, C. (2020). Social distancing meet social media: Digital tools for connecting students, teachers, and citizens in an emergency. Information and Learning Sciences, 121(5/6), 341-352. https://doi.org/10.1108/ILS-04-2020-0134.

Crawford, J., Butler-Henderson, K., Rudolph, J., Malkawi, B., Glowatz, M., Burton, R., Magni, P., \& Lam, S. (2020). COVID-19: 20 countries' higher education intra-period digital pedagogy responses. Journal of Applied Learning and Teaching, 3(1), 1-20. https://doi.org/10.37074/jalt.2020.3.1.7.

de Oliveira Araújo, F. J., de Lima, L. S. A., Cidade, P. I. M., Nobre, C. B., \& Neto, M. L. R. (2020). Impact of SARS-Cov-2 and its reverberation in global higher education and mental health. Psychiatry Research, 288, 112977. https://doi.org/10.1016/j. psychres.2020.112977.

D'Adamo, I., Gastaldi, M., \& Morone, P. (2020). The post COVID-19 green recovery in practice: Assessing the profitability of a policy proposal on residential photovoltaic plants. Energy Policy, 147, 111910. https://doi.org/10.1016/j.enpol.2020.111910.
D'Adamo, I., \& Rosa, P. (2020). How do you see infrastructure? Green energy to provide economic growth after COVID-19. Sustainability (Switzerland), 12(11), 10-12. https://doi.org/10. 3390/su12114738.

Donitsa-Schmidt, S., \& Ramot, R. (2020). Opportunities and challenges: Teacher education in Israel in the Covid-19 pandemic. Journal of Education for Teaching. https://doi.org/ 10.1080/02607476.2020.1799708.

Drane, C., Vernon, L., \& Shea, S. O. (2020). The impact of 'Learning at Home' on The educational outcomes of vulnerable children in Australia during the COVID-19 pandemic. Literature Review Prepared by the National Centre for Student Equity in Higher Education. Curtin University, Australia. https://apo.org.au/node/ 303566.

Emon, E. K. H., Alif, A. R., \& Islam, M. S. (2020). Impact of COVID-19 on the institutional education system and its associated students in Bangladesh. Asian Journal of Education and Social Studies. https://doi.org/10.9734/ajess/2020/v11i230288.

Evans, S., \& Bahrami, H. (2020). Super-flexibility in practice: Insights from a crisis. Global Journal of Flexible Systems Management, 21(3), 207-214. https://doi.org/10.1007/s40171020-00246-6.

Evans, D. J. R., Bay, B. H., Wilson, T. D., Smith, C. F., Lachman, N., \& Pawlina, W. (2020). Going virtual to support anatomy education: A STOPGAP in the midst of the Covid-19 pandemic. Anatomical Sciences Education, 13(3), 279-283. https://doi.org/ 10.1002/ase.1963.

Filho, W. L., Shiel, C., do Paço, A., \& Brandli, L. (2015). Putting sustainable development in practice: Campus greening as a tool for institutional sustainability efforts. Sustainability in Higher Education. https://doi.org/10.1016/B978-0-08-100367-1.000019.

Fissi, S., Romolini, A., Gori, E., \& Contri, M. (2021). The path toward a sustainable green university: The case of the University of Florence. Journal of Cleaner Production, 279, 123655. https://doi.org/10.1016/j.jclepro.2020.123655.

Franchi, T. (2020). The impact of the Covid-19 pandemic on current anatomy education and future careers: A student's perspective. Anatomical Sciences Education, 13(3), 312-315. https://doi.org/ 10.1002/ase. 1966.

Gayithri, J., Deborah, F., Kaffai, Y. B., \& Joseph, C. (2020). Supporting making online: The role of artifact, teacher and peer interactions in crafting electronic textiles. Information and Learning Sciences, 121(5/6), 381-390. https://doi.org/10.1108/ ILS-04-2020-0111.

Hasan, N., \& Bao, Y. (2020). Impact of "e-Learning crack-up" perception on psychological distress among college students during COVID-19 pandemic: A mediating role of "fear of academic year loss." Children and Youth Services Review, 118 , 105355. https://doi.org/10.1016/j.childyouth.2020.105355.

Hossain, N. U. I., Nagahi, M., Jaradat, R., Stirgus, E., \& Keating, C. B. (2020). The effect of an individual's education level on their systems skills in the system of systems domain. Journal of Management Analytics, 7(4), 510-531. https://doi.org/10.1080/ 23270012.2020 .1811788$.

Izumi, T., Sukhwani, V., Surjan, A., \& Shaw, R. (2020). Managing and responding to pandemics in higher educational institutions: Initial learning from COVID-19. International Journal of Disaster Resilience in the Built Environment, 12(1), 51-66. https://doi.org/10.1108/IJDRBE-06-2020-0054.

Ju, Y., Liang, Y., Luis, M., Santibanez Gonzalez, E. D. R., Giannakis, M., Dong, P., \& Wang, A. (2020). A new framework for healthcare waste disposal alternative selection under multi-granular linguistic distribution assessment environment. Computers and Industrial Engineering, 145, 106489. https://doi.org/10.1016/j. cie.2020.106489. 
Kahraman, C., Suder, A., \& Cebi, S. (2013). Fuzzy multi-criteria and multi-experts evaluation of government investments in higher education: The case of Turkey. Technological and Economic Development of Economy, 19(4), 549-569. https://doi.org/10. 3846/20294913.2013.837110.

Karmaker, C. L., Ahmed, T., Ahmed, S., Ali, S. M., Moktadir, M. A., \& Kabir, G. (2021). Improving supply chain sustainability in the context of COVID-19 pandemic in an emerging economy: Exploring drivers using an integrated model. Sustainable Production and Consumption, 26, 411-427. https://doi.org/10.1016/ j.spc.2020.09.019.

Kaur, I., Shri, C., \& Mital, K. M. (2015). A flexible approach towards effective teaching: Use of social media by teachers. Global Journal of Flexible Systems Management, 16(4), 391-403. https://doi.org/10.1007/s40171-015-0113-1.

Kaur, J., Sidhu, R., Awasthi, A., \& Srivastava, S. K. (2019). A Pareto investigation on critical barriers in green supply chain management. International Journal of Management Science and Engineering Management, 14(2), 113-123. https://doi.org/10.1080/ 17509653.2018 .1504237$.

Khan, N. Z., Ansari, T. S. A., Siddiquee, A. N., \& Khan, Z. A. (2019). Selection of E-learning websites using a novel Proximity Indexed Value (PIV) MCDM method. Journal of Computers in Education, 6(2), 241-256. https://doi.org/10.1007/s40692-01900135-7.

König, J., Jäger-Biela, D. J., \& Glutsch, N. (2020). Adapting to online teaching during COVID-19 school closure: Teacher education and teacher competence effects among early career teachers in Germany. European Journal of Teacher Education, 43(4), 1-15. https://doi.org/10.1080/02619768.2020.1809650.

Kumar, R., Singh, K., \& Jain, S. K. (2019). Agile manufacturing: A literature review and Pareto analysis. International Journal of Quality and Reliability Management, 37(2), 207-222. https://doi. org/10.1108/IJQRM-12-2018-0349.

Lee, B. Y., Brown, S. T., Cooley, P., Potter, M. A., Wheaton, W. D., Voorhees, R. E., Stebbins, S., Grefenstette, J. J., Zimmer, S. M., Zimmerman, R. K., Assi, T. M., Bailey, R. R., Wagener, D. K., \& Burke, D. S. (2010). Simulating school closure strategies to titigate an influenza epidemic. Journal of Public Health Management and Practice, 16(3), 252-261. https://doi.org/10.1097/ PHH.0b013e3181ce594e.

Lewin, K. M. (2020). Contingent reflections on coronavirus and priorities for educational planning and development. Prospects, 49(1), 17-24.

Liu, Z., \& Ming, X. (2019). A framework with revised roughDEMATEL to capture and evaluate requirements for smart industrial product-service system of systems. International Journal of Production Research, 57(22), 7104-7122. https:// doi.org/10.1080/00207543.2019.1577566.

Loxton, E. A., Schirmer, J., \& Kanowski, P. (2013). Designing, implementing and monitoring social impact mitigation strategies: Lessons from forest industry structural adjustment packages. Environmental Impact Assessment Review, 42, 105-115. https://doi.org/10.1016/j.eiar.2012.11.003.

Luo, N., Zhang, M., \& Qi, D. (2017). Effects of different interactions on students' sense of community in e-learning environment. Computers and Education, 115, 153-160. https://doi.org/10. 1016/j.compedu.2017.08.006.

Maher, C. S., Hoang, T., \& Hindery, A. (2020). Fiscal Responses to COVID-19: Evidence from Local Governments and Nonprofits. Public Administration Review, 80(4), 644-650. https://doi.org/ 10.1111/puar.13238.

Marsh, J. A., Allbright, T. N., Brown, D. R., Bulkley, K. E., Strunk, K. O., \& Harris, D. N. (2020). The process and politics of educational governance change in New Orleans, Los Angeles, and Denver. American Educational Research Journal, 58(1), 107-159. https://doi.org/10.3102/0002831220921475.

Martin, F., \& Bolliger, D. U. (2018). Engagement matters: Student perceptions on the importance of engagement strategies in the online learning environment. Online Learning, 22(1), 205-222.

Martin, F., Sun, T., \& Westine, C. D. (2020). A systematic review of research on online teaching and learning from 2009 to 2018. Computers and Education, 159(April), 104009. https://doi.org/ 10.1016/j.compedu.2020.104009.

McKee, G., Sims, K. R. E., \& Rivkin, S. G. (2015). Disruption, learning, and the heterogeneous benefits of smaller classes. Empirical Economics, 48(3), 1267-1286. https://doi.org/10. 1007/s00181-014-0810-1.

Medrano, M., Cadenas-Sanchez, C., Oses, M., Arenaza, L., Amasene, M., \& Labayen, I. (2020). Changes in lifestyle behaviours during the COVID-19 confinement in Spanish children: A longitudinal analysis from the MUGI project. Pediatric Obesity. https://doi. org/10.1111/ijpo.12731.

Milosavljevic, P., Pavlovic, D., Rajic, M., Pavlovic, A., \& Fragassa, C. (2018). Implementation of quality tools in higher education process. International Journal of Continuing Engineering Education and Life Long Learning, 28(1), 24-36. https://doi.org/10. 1504/IJCEELL.2018.090248.

Muhammad, M. N., \& Cavus, N. (2017). Fuzzy DEMATEL method for identifying LMS evaluation criteria. Procedia Computer Science, 120, 742-749. https://doi.org/10.1016/j.procs.2017.11. 304.

Murphy, M. P. A. (2020). COVID-19 and emergency eLearning: Consequences of the securitization of higher education for postpandemic pedagogy. Contemporary Security Policy, 41(3), 492-505. https://doi.org/10.1080/13523260.2020.1761749.

Nicola, M., Alsafi, Z., Sohrabi, C., Kerwan, A., Al-jabir, A., Iosifidis, C., Agha, M., \& Agha, R. (2020). The socio-economic implications of the coronavirus pandemic (COVID-19): A review. International Journal of Surgery, 78, 185-193. https:// doi.org/10.1016/j.ijsu.2020.04.018.

Oke, A., \& Fernandes, F. A. P. (2020). Innovations in teaching and learning: Exploring the perceptions of the education sector on the 4th industrial revolution (4IR). Journal of Open Innovation: Technology, Market, and Complexity. https://doi.org/10.3390/ JOITMC6020031.

Paul, S. K., \& Chowdhury, P. (2020). Strategies for managing the impacts of disruptions during COVID-19: an example of toilet paper. Global Journal of Flexible Systems Management, 21(3), 283-293. https://doi.org/10.1007/s40171-020-00248-4.

Pikulski, P. J., Pella, J. E., Casline, E. P., Hale, A. E., Drake, K., \& Ginsburg, G. S. (2020). School connectedness and child anxiety. Journal of Psychologists and Counsellors in Schools, 30(1), 13-24. https://doi.org/10.1017/jgc.2020.3.

Polas, M. R. H., \& Raju, V. (2021). Technology and entrepreneurial marketing decisions during COVID-19. Global Journal of Flexible Systems Management, 5, 6-10. https://doi.org/10.1007/ s40171-021-00262-0.

Qin, F., Song, Y., Nassis, G. P., Zhao, L., Dong, Y., Zhao, C., Feng, Y., \& Zhao, J. (2020). Physical activity, screen time, and emotional well-being during the 2019 novel coronavirus outbreak in China. International Journal of Environmental Research and Public Health, 17(14), 1-16. https://doi.org/10. 3390/ijerph17145170.

Raju, V. (2021). Implementing flexible systems in doctoral viva defense through virtual mechanism. Global Journal of Flexible Systems Management. https://doi.org/10.1007/s40171-02100264-y.

Ranjan, R., Chatterjee, P., \& Chakraborty, S. (2015). Evaluating performance of engineering departments in an Indian University 
using DEMATEL and compromise ranking methods. Opsearch, 52(2), 307-328. https://doi.org/10.1007/s12597-014-0186-1.

Rashid, S., \& Yadav, S. S. (2020). Impact of Covid-19 pandemic on higher education and research. Indian Journal of Human Development, 14(2), 340-343. https://doi.org/10.1177/ 0973703020946700.

Ratten, V., \& Jones, P. (2020). Covid-19 and entrepreneurship education: Implications for advancing research and practice. International Journal of Management Education. https://doi.org/ 10.1016/j.ijme.2020.100432.

Reimers, F. M., \& Andreas, S. (2020). A framework to guide an education response to the COVID - 19 pandemic of 2020. In Oecd (Vol. 14). https://oecd.dam-broadcast.com/pm_7379_126_ 126988-t631xosohs.pdf.

Richmond, G., Bartell, T., Cho, C., Gallagher, A., He, Y., Petchauer, E., \& Curiel, L. C. (2020a). Home/school: Research imperatives, learning settings, and the COVID-19 pandemic. Journal of Teacher Education, 71(5), 503-504. https://doi.org/10.1177/ 0022487120961574

Richmond, G., Cho, C., Gallagher, H. A., He, Y., \& Petchauer, E. (2020b). The critical need for pause in the COVID-19 Era. Journal of Teacher Education, 71(4), 375-378. https://doi.org/ 10.1177/0022487120938888.

Romprasert, S., \& Monjagapate, J. (2020). Digitized educational system. . IntechOpen. https://doi.org/10.5772/intechopen.87781.

Sagnak, M., Ada, N., Kazancoglu, Y., \& Tayaksi, C. (2017). Quality function deployment application for improving quality of education in business schools. Journal of Education for Business, 92(5), 230-237. https://doi.org/10.1080/08832323. 2017.1339661s.

Sambasivam, V. P., Thiyagarajan, G., Kabir, G., Ali, S. M., Khan, S. A. R., \& Yu, Z. (2020). Selection of winter season crop pattern for environmental-friendly agricultural practices in India. Sustainability (Switzerland). https://doi.org/10.3390/su12114562.

Sebastian, S., \& Nikol, R. (2020). Promoting interaction in online distance education: Designing, implementing and supporting collaborative learning. Information and Learning Sciences, 121(5/6), 251-260. https://doi.org/10.1108/ILS-04-2020-0090.

Severo, E. A., De Guimarães, J. C. F., \& Dellarmelin, M. L. (2021). Impact of the COVID-19 pandemic on environmental awareness, sustainable consumption and social responsibility: Evidence from generations in Brazil and Portugal. Journal of Cleaner Production, 286, 124947. https://doi.org/10.1016/j.jclepro.2020. 124947.

Shukla, S. K., Sushil, \& Sharma, M. K. (2019). Managerial paradox toward flexibility: Emergent views using thematic analysis of literature. Global Journal of Flexible Systems Management, 20(4), 349-370. https://doi.org/10.1007/s40171-019-00220-x.

Shuqin, C., Minyan, L., Hongwei, T., Xiaoyu, L., \& Jian, G. (2019). Assessing sustainability on Chinese university campuses: Development of a campus sustainability evaluation system and its application with a case study. Journal of Building Engineering, 24, 100747. https://doi.org/10.1016/j.jobe.2019.100747.

Singh, B., \& Singh, R. (2020). Nursing education during COVID-19 pandemic: Way forward for teaching hospitals in Nepal. Europasian Journal of Medical Sciences. https://doi.org/10. 46405/ejms.v2i2.126.

Sintema, E. J. (2020). Effect of COVID-19 on the performance of grade 12 students: Implications for STEM education. Eurasia Journal of Mathematics, Science and Technology Education, 16(7), 1-6. https://doi.org/10.29333/EJMSTE/7893.

Song, W., \& Cao, J. (2017). A rough DEMATEL-based approach for evaluating interaction between requirements of product-service system. Computers and Industrial Engineering, 110, 353-363. https://doi.org/10.1016/j.cie.2017.06.020.
Song, W., Zhu, Y., \& Zhao, Q. (2020). Analyzing barriers for adopting sustainable online consumption: A rough hierarchical DEMATEL method. Computers and Industrial Engineering, 140, 106279. https://doi.org/10.1016/j.cie.2020.106279.

Sunder, M. V. (2016). Lean Six Sigma in higher education institutions. International Journal of Quality and Service Sciences, 8(2), 159-178. https://doi.org/10.1108/IJQSS-042015-0043.

Surana, K., Singh, A., \& Sagar, A. D. (2020). Strengthening science, technology, and innovation-based incubators to help achieve sustainable development goals: Lessons from India. Technological Forecasting and Social Change, 157, 120057. https://doi. org/10.1016/j.techfore.2020.120057.

Sushil. (2015). Creating flexibility through technological and attitudinal change. Global Journal of Flexible Systems Management, 16(4), 309-311. https://doi.org/10.1007/s40171-015-0112-2.

Tabor, J. W. (2020). Chaos: Exploring an engaging online model for rapid application during the pandemic. Educational Technology Research and Development, 0123456789, 1-4. https://doi.org/ 10.1007/s11423-020-09878-y.

Talidong, K. J. B., \& Toquero, C. M. D. (2020). Philippine teachers' practices to deal with anxiety amid COVID-19. Journal of Loss and Trauma, 25(6-7), 573-579. https://doi.org/10.1080/ 15325024.2020.1759225.

Tembo Silungwe, C. K., \& Khatleli, N. (2020). An analysis of the allocation of pertinent risks in the Zambian building sector using Pareto analysis. International Journal of Construction Management, 20(4), 321-334. https://doi.org/10.1080/15623599.2018. 1484853.

UNESCO. (2020). School closures caused by Coronavirus (Covid19). In Unesco. https://en.unesco.org/covid19/educationre sponse.

Van den Beemt, A., MacLeod, M., Van der Veen, J., Van de Ven, A., van Baalen, S., Klaassen, R., \& Boon, M. (2020). Interdisciplinary engineering education: A review of vision, teaching, and support. Journal of Engineering Education, 109(3), 508-555. https://doi.org/10.1002/jee.20347.

Wilson, M. L., Ritzhaupt, A. D., \& Cheng, L. (2020). The impact of teacher education courses for technology integration on preservice teacher knowledge: A meta-analysis study. Computers and Education, 156, 103941. https://doi.org/10.1016/j.compedu. 2020.103941.

Zar, H. J., Dawa, J., Fischer, G. B., \& Castro-Rodriguez, J. A. (2020). Challenges of COVID-19 in children in low-and middle-income countries. Paediatric Respiratory Reviews, 35, 70-74. https:// doi.org/10.1016/j.prrv.2020.06.016.

Publisher's Note Springer Nature remains neutral with regard to jurisdictional claims in published maps and institutional affiliations.

\section{Key Questions Reflecting Applicability in RealLife}

1. What are the significant challenges for the education sector before and after the implementation of online learning due to COVID-19 outbreak?

2. What are the flexible strategies to recover from those challenges of COVID-19 outbreak for the education sector?

3. What are the contextual relationships among the flexible strategies to handle the challenges of educational institutions? 


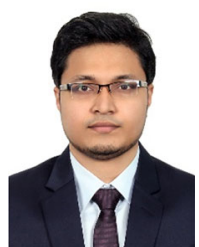

Sayem Ahmed currently works as an Assistant Professor of Industrial and Production Engineering (IPE) in the Department of Mechanical and Production Engineering (MPE) at Ahsanullah University of Science and Technology (AUST), Dhaka, Bangladesh. His current research interests and areas include- Green and Sustainable Supply Chain, Digital Supply Chain and Industry 4.0, Humanitarian Logistics, Disruption and Risk Assessment, Scheduling and Project Management, Production Planning and Control, Quality Management and Control, Multi-Criteria Decision Making (MCDM) Techniques, Artificial Intelligence and Machine Learning, Simulation and Multi-Objective Optimization, Online Teaching and Learning, Education Policy. His research appears in International Journal of Logistics Research and Applications, International Journal of Applications of Fuzzy Sets and Artificial Intelligence, Sustainable Production and Consumption, etc. He serves as a reviewer in various renown journal like International Journal of Productivity and Performance Management.

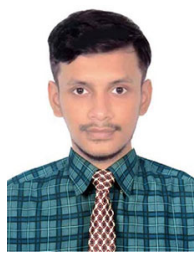

Hasin Md. Muhtasim Taqi currently works as a Lecturer in the Department of Mechanical and Production Engineering (MPE) at Ahsanullah University of Science and Technology (AUST), Dhaka, Bangladesh. His current research interests include- Supply Chain Network Design, Green and Sustainable Supply Chain, Industry 4.0, MultiObjective Optimization, MCDM Techniques. His research appears in International Journal of Logistics Research and Applications, Sustainability, International Journal of Applications of Fuzzy Sets and Artificial Intelligence.

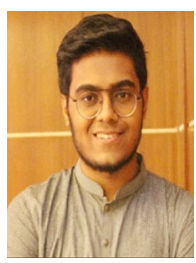

Yeasir Iqbal Farabi is pursuing his Bachelor of Science degree in Industrial and Production Engineering (IPE) from the Department of Mechanical and Production Engineering (MPE) at Ahsanullah University of Science and Technology (AUST). He has firm research interest in Optimization Technique, Operation Management and Supply Chain management.

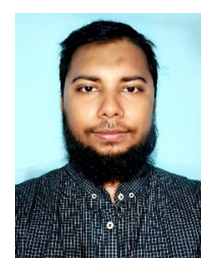

Mohiuddin Sarker is a Bachelor of Science student of Industrial and Production Engineering (IPE) from the Department of Mechanical and Production Engineering (MPE) at Ahsanullah University of Science and Technology (AUST). His research interests lie in Supply Chain Management, Operations Management and Multi-Criteria Decision Making (MCDM) techniques.

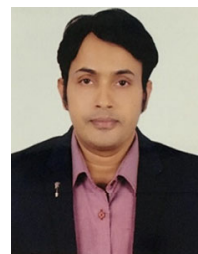

Dr. Syed Mithun Ali is an Associate Professor in the Department of Industrial and Production Engineering in Bangladesh University of Engineering and Technology (BUET). He holds a $\mathrm{Ph}$.D. majoring in supply chain management from the Nagoya Institute of Technology, Japan. His research appears in the Journal of Cleaner Production, International Journal of Production Economics, Journal of Retailing and Consumer Services, International Journal of Production Research, Sustainable Production and Consumption, Industrial Management and Data Systems, Computers and Industrial Engineering and so on. His current research interest includes logistics and supply chain management and supply chain risk management and tying that to supply chain sustainability.

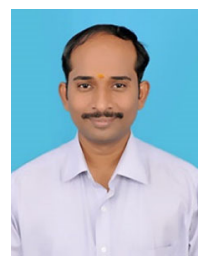

Dr. Bathrinath Sankaranarayanan is an Associate Professor in the Department of Mechanical Engineering, Kalasalingam Academy of Research and Education, Krishnankoil, Tamilnadu, India. His current area of research includes Industry 4.0, Supply Chain Management, Circular Economy, Risk Assessment, Multi-Criteria Decision Making, Scheduling, Optimization of process parameters, Soft Computing and Artificial intelligence. He has obtained his PostDoctoral Fellowship in University of Southern Denmark, Odense, Denmark. He has also obtained his Young Scientist Fellowship from Tamilnadu State Council for Science and Technology (TNSCST). He has published 30 papers in journal of national/international repute and presented a number of papers in various conferences/symposia in India and abroad. He is presently guiding a number of master/doctoral research scholars. Dr. S. Bathrinath can be contacted at: bathri@gmail.com 